\title{
Potassium Bromide (KBr): Transformasi ionik dan sifat temodinamika dalam Larutan
}

\author{
Puti Ika Artika ${ }^{1}$, Rahadian Zainul ${ }^{2}$ \\ ${ }^{1}$ Chemistry Education, FMIPA, Universitas Negeri Padang, Indonesia \\ ${ }^{2}$ Physical Chemistry Laboratory, FMIPA, Universitas Negeri Padang, Indonesia \\ 1E-mail : putiikaartika@gmail.com \\ 2E-mail : rahadianzmsiphd@yahoo.com
}

\begin{abstract}
Abstrak : Kalium bromida merupakan garam ionik yang dapat larut dalam air dengan rumus kimia KBr. Kelarutan senyawa kalium bromida menyebabkan terjadinya interaksi antara garam ionik dengan suatu sistem biologis, mengamati sifat interaksi dari masing-masing molekul merupakan suatu proses yang sangat kompleks dan akan sulit jika melalui percobaan. Penelitian ini bertujuan sebagai salah satu cara untuk memahami interaksi senyawa ionik kalium bromida dengan molekul lain. Metode yang digunakan adalah melalui pemodelan menggunakan aplikasi ChemOffice 11.0, dan data simulasi yang diperoleh dari jurnal penelitian model kalium bromida, serta data dari hasil review beberapa jurnal penelitian yang berkaitan dengan senyawa kalium bromida. Sifat-sifat termokimia dari senyawa kalium bromida dalam fase liquid $\Delta_{f} H^{0}=-76,49 \mathrm{~kJ} / \mathrm{mol}, S^{0}=105,54$ $\mathrm{J} / \mathrm{molK}, \Delta G^{0}=-378.8 \mathrm{~J} / \mathrm{molK}$, dan $\mathrm{C}_{\mathrm{p}}=52.07 \mathrm{~J} / \mathrm{molK}$. Interaksi atau transformasi suatu ion dapat dilihat dari pengaruh aspek sifat termodinamika senyawa ion (kalium bromida) dalam suatu larutan melalui perhitungan viskositas, kecepatan hanyut,dan mobilitas yang akan mempengaruhi tingkat konduktivitas senyawa kalium bromida. Kalium bromida memiliki Kecepatan hayut 2,085 V/cm, konduktivitas listrik 5,2 Ms/cm untuk persen massa $0,5 \%$, mobilitas relative ion $\mathrm{K}^{+}$dan $\mathrm{Br}^{2}$ adalah 1,000 dan 1,063 dan tingkat viskositas $1,18 \mathrm{mPa} \cdot \mathrm{s}$ pada suhu $747^{\circ} \mathrm{C}$.
\end{abstract}

Keyword: ion, molekul, konduktivitas, konstanta elektrik viskositas, daya hanyut, mobilitas

\section{Pendahuluan}

Kalium bromida $(\mathrm{KBr})$ banyak digunakan dalam kehidupan, salah satu contohnya adalah dalam bentuk garam. Kalium bromida, merupakan garam ionik yang khas. Garam ini dapat terdisosiasi sempurna dan mendekati pH 7 dalam larutan berair. Senyawa ini berfungsi sebagai sumber ion bromida. Kalium bromida dapat terionisasi didalam air menjadi kation $\mathrm{K}^{+}$dan anion $\mathrm{Br}^{-}$.

Kalium bromida dapat di sintesis dengan mereaksikan kalium karbonat dengan besi(III,III, II) bromida, $\mathrm{Fe}_{3} \mathrm{Br}_{8}$, dibuat dengan memberi perlakuan pada besi bekas di bawah air dengan kelebihan brom.

$$
4 \mathrm{~K}_{2} \mathrm{CO}_{3}+\mathrm{Fe}_{3} \mathrm{Br}_{8} \rightarrow 8 \mathrm{KBr}+\mathrm{Fe}_{3} \mathrm{O}_{4}+4 \mathrm{CO}_{2}
$$

Berikut reaksi pembuatan perak bromida untuk film fotografi melalui reaksi ${ }^{[250]}$ kalium bromida dengan perak nitrat:

$$
\mathrm{KBr}_{(\mathrm{aq})}+\mathrm{AgNO}_{3(\mathrm{aq})} \rightarrow \mathrm{AgBr}_{(\mathrm{s})}+\mathrm{KNO}_{3(\mathrm{aq})}
$$

Larutan bromida $\mathrm{Br}^{-}$dapat membentuk kompleks ketika direaksikan dengan beberapa halida logam seperti tembaga(II) bromida:

$2 \mathrm{KBr}_{(\mathrm{aq})}+\mathrm{CuBr}_{2(\mathrm{aq})} \rightarrow \mathrm{K}_{2}\left[\mathrm{CuBr}_{4}\right]_{(\mathrm{aq})}$

Kalium bromida fasa ${ }^{[248-249]}$ padat berupa bubuk kristal putih. Kalium bromida memiliki kelarutan yang tinggi dalam air dan tidak dapat larut dalam pelarut asetonitril. Kalium bromida memiliki rasa manis, sedangkan pada konsentrasi yang lebih tinggi rasanya menjadi pahit, dan 
berubah menjadi asin saat konsentrasinya semakin tinggi, hal ini terjadi dalam larutan berair encer, disebabkan karena sifat dari ion kalium, natrium ${ }^{(193-200)}$ bromida yang rasanya asin pada konsentrasi apapun. Dalam konsentrasi tinggi, kalium bromida merusak selaput lambung, dapat menyebabkan mual dan muntah ,hal ini merupakan efek khas dari semua garam kalium yang larut.

\section{Metode}

Metode yang digunakan adalah melalui data simulasi yang diperoleh dari jurnal penelitian model kalium bromida, pemodelan menggunakan aplikasi ChemOffice Ultra 11.0 serta melalui jurnal lain yang memuat hasil penelitian yang berkaitan dengan senyawa kalium bromida. Penelitian ini bertujuan sebagai salah satu cara untuk memahami interaksi senyawa ionik kalium bromida dengan molekul lain. Proses menganalisis menggunakan aplikasi ChemBioDraw Ultra 11.0 dan ChemBio3D Ultra 11.0 yaitu dengan menghitung MMFF94 dari molekul kalium bromida yang terdiri dari MMFF94 minimization, MMFF94 dynamics dan MMFF94 Energy dan Gradient.

Pada bagian ChemBio3D, struktur $\mathrm{KBr}$ diubah menjadi bentuk 3 dimensi dan kemudian dianalisis dengan menghitung MMFF94 dari masing-masing molekul yang terdiri atas MMFF94 Minimization, MMFF94 Energy dan Gradient, MMFF94 Molecular Dynamics. Langkahnya dengan klik pada menu calculation, pilih MMFF94 kemudian klik calculate MMFF94 Energy dan Gradient lalu klik run. Dengan langkah yang sama dilakukan untuk menentukan molecular dynamics dan minimization.

Interaksi antara senyawa garam dengan suatu molekul lain merupakan proses yang sangat kompleks dan sulit untuk mengamati sifat dari interaksi yang terjadi pada masing-masing molekul. Oleh karena itu, salah satu cara untuk memahami interaksi dari senyawa ionik $\mathrm{KBr}$ dengan molekul lain adalah dengan menggunakan data simulasi, kemudian melihat aspek termodinamika yang mempengaruhi transpor ion dari senyawa $\mathrm{KBr}$. Berdasarkan hasil review beberapa jurnal penelitian mengenai senyawa kalium bromida. Metode yang biasa digunakan adalah penyesuaian parameter model dengan hasil eksperimen untuk nilai kerapatan, struktur dan sistem nyata lainnya dari senyawa $\mathrm{KBr}$ pada tekanan dan suhu tertentu. Kemudian, hasil yang diperoleh untuk sifat termodinamika dan dinamis dari model dibandingkan dengan hasil percobaan.

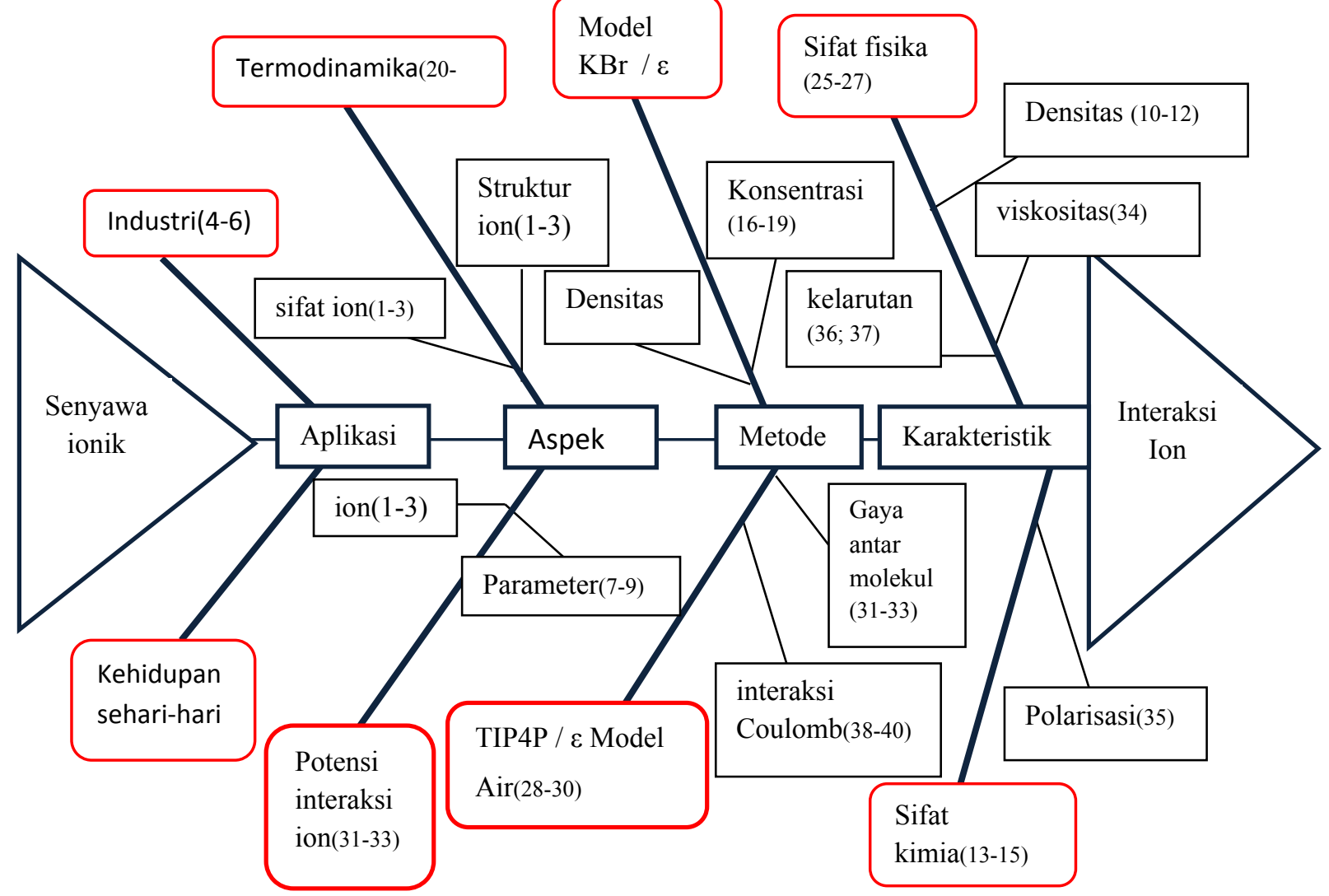




\section{Hasil Dan Pembahasan}

\subsection{Karakteristik Kalium Bromida}

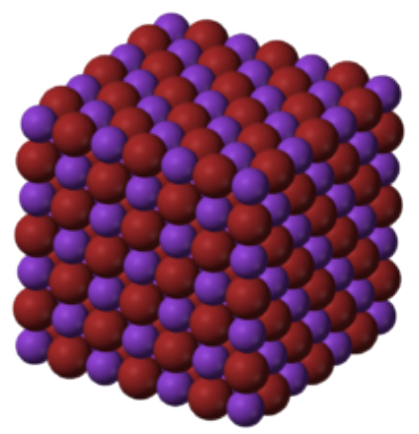

Gambar 1.Gambar susunan atom kalium bromida Sumber : https://id.wikipedia.org/wiki/Kalium_bromida
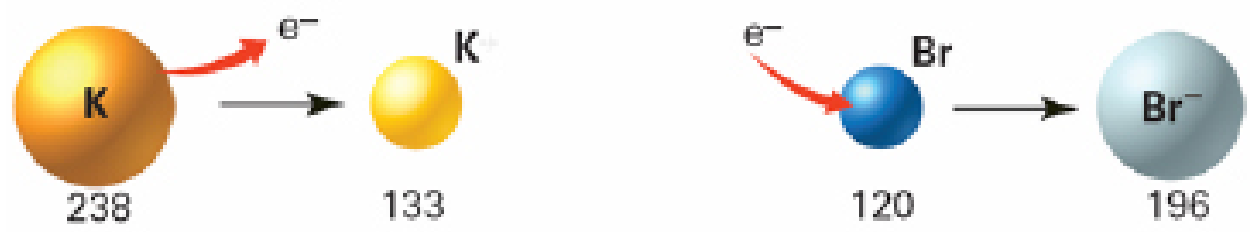

Gambar 2. Ukuran jari-jari kalium dan bromin serta ukuran anion dan kation Sumber.https://mdesyra.wordpress.com/2012/03/07/analisis-kualitatif-anion/

Ikatan antara Kalium dan Bromin dalam senyawa $\mathrm{KBr}$ adalah ikatan ionik. Karena terjadi transfer elektron dari Kalium ke Bromin, sehingga menghasilkan pembentukan ion $\mathrm{K}^{+}$(kation) dan Br- (anion), yang yang mengalami daya tarik elektrostatik. Brom adalah unsur non logam dan potassium adalah unsur logam ${ }^{[20-221]}$. Berdasarkan Skala elektronegeritas Linus memberikan nilai antara 0 dan 4 untuk unsur yang menggambarkan daya tarik elektron dalam ikatan kimia ${ }^{[222-226 ; 246]}$. Jika diatas 2,1 adalah ikatan ionik. $\mathrm{K}$ memiliki elektronegativitas 0,82 dan $\mathrm{Br}$ adalah 2,96. Perbedaannya adalah 2,14, menunjukkan bahwa ikatan yang terbentuk adalah ikatan ionik.
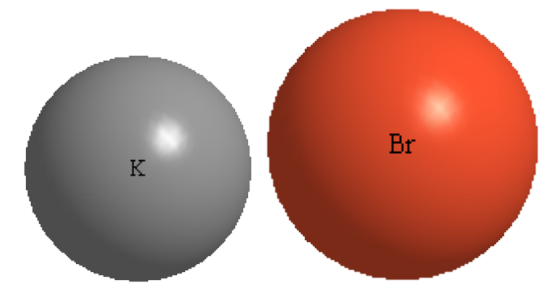

\section{Analysis Chemoffice}

Chemical Formula : K

Exact Mass : 38,96

Molecular Weight : 39,10

$\mathrm{m} / \mathrm{z}: 38,96,(100,0 \%), 40,96(7,2 \%)$

elemen Analysis : K, 100.00

\author{
Analysisi Chemoffice \\ Chemical Formula : $\mathrm{Br}$ \\ Exact Mass :78,92 \\ Molecular Weight : 79,90 \\ $\mathrm{m} / \mathrm{z}: 78,92(100,0 \%), 80,90(7,2 \%)$ \\ elemen Analysis :Br, 100.00
}

Gambar 3. Analisis Jari-jari atom per unit atomic

(Chemoffice 3D Version 11.0, Perkinelmer Informatic. Inc, 2011) 


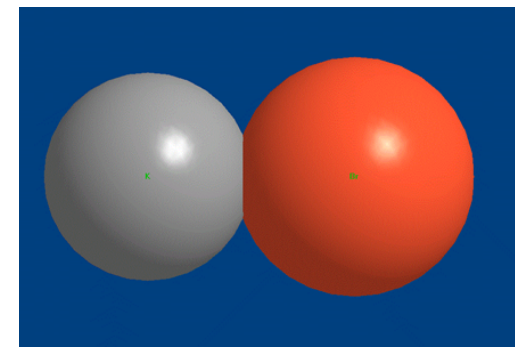

(a)

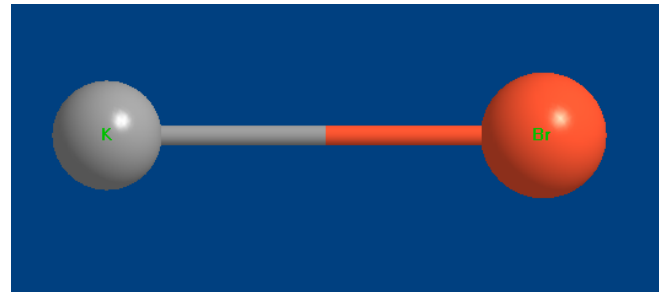

(b)

Gambar 4. Analisis Senyawa ionik $\mathrm{KBr}$ (a) space filling (b) ball and stick

(Chemoffice 3D Version 11.0, Perkinelmer Informatic. Inc, 2011)

Analysis Chemoffice

Chemical Formula : BrK

Exact Mass : 117,88

Molecular Weight : 119,00

$\mathrm{m} / \mathrm{z}: 119,88$ (100,0\%), 117,88 (95,7\%), 121,88 (6,7\%)

elemen Analysis : Br, 67,14; K,32,86

Optimasi Molekul KBr menggunakan Moleculer Mechanic (MMFF94)

Optimasi molecule KBr dilakukan dengan Merk Molecular Force Field (MMFF94) dan menghasilkan output data dalam bentuk data geometri atom-atom dalam molekul dan energi optimumnya. Adapun hasil output yang diperoleh sebagai berikut :

\subsubsection{Optimasi MMFF94 Minimization} -MMFF94 Minimization-

Iteration 5: Minimization terminated normally because the gradient norm is less than the minimum gradient norm

Final Energy: 2.27134e-006 kcal/mol

Calculation ended

\subsubsection{Optimasi MMFF94 Energy dan Gradient}

-Calculate MMFF94 Energy and Gradient

The total energy for this frame: $0.000 \mathrm{kcal} / \mathrm{mol}$

The RMS Gradient is: $\quad 0.023$

\subsubsection{Optimasi MMFF94 Molecular Dynamics}

-MMFF94 Molecular Dynamics

Iteration 1: energy $=2.271 \mathrm{e}-006 \mathrm{kcal} / \mathrm{mol}$

Iteration 2 : energy $=2.271 \mathrm{e}-006 \mathrm{kcal} / \mathrm{mol}$

Iteration $3:$ energy $=2.271 \mathrm{e}-006 \mathrm{kcal} / \mathrm{mol}$

Iteration $4:$ energy $=2.271 \mathrm{e}-006 \mathrm{kcal} / \mathrm{mol}$

Iteration 5: energy $=2.271 \mathrm{e}-006 \mathrm{kcal} / \mathrm{mol}$

Iteration 6: energy $=2.271 \mathrm{e}-006 \mathrm{kcal} / \mathrm{mol}$

Iteration 7: energy $=2.271 \mathrm{e}-006 \mathrm{kcal} / \mathrm{mol}$

Iteration $8:$ energy $=2.271 \mathrm{e}-006 \mathrm{kcal} / \mathrm{mol}$

Iteration 9: energy $=2.271 \mathrm{e}-006 \mathrm{kcal} / \mathrm{mol}$

Iteration 10: energy $=2.271 \mathrm{e}-006 \mathrm{kcal} / \mathrm{mol}$

4. Calculation ended

Jari-jari molekul $\mathrm{Br}$

MM2 Constant Value Quality

Cubic stretch constant-2.000 4

Quartic stretch constant2.333 4

Sextic bending constant $(* 10 * * 8) 7.000$ 
Cutoff distance for charge/charge interactions35.000 4

Cutoff distance for charge/dipole interactions25.000 4

Cutoff distance for dipole/dipole interactions $18.000 \quad 4$

Cutoff distance for van der Waals interactions $10.000 \quad 4$

\section{MM2 c3dAtomRadius Eps Weight Reduct Lone Pairs Quality

$\begin{array}{lllllll}13 & 2.180 & 0.320 & 78.918 & 0.000 & 0 & 4\end{array}$

\section{Kalium}

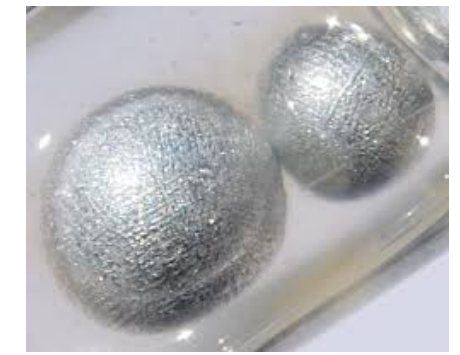

Gambar 5. Logam Kalium

Sumber. https://en.wikipedia.org/wiki/Potassium

$\begin{array}{lc}\text { Jari-jari atom } & : 243 \mathrm{pm} \\ \text { Jari-jari kovalen } & : 203 \mathrm{pm} \\ \text { Jari-jari van der wals } & : 275 \mathrm{pm} \\ \text { Jari-jari ion kalium } & : 133 \mathrm{pm} \\ \text { Titik leleh } & : 63,38^{\circ} \mathrm{C} \\ \text { Titik didih } & : 759{ }^{\circ} \mathrm{C}\end{array}$

Kalium dengan nomor atom 19 memiliki massa atom 39,00983 dengan densitas $0,856 \mathrm{~g} / \mathrm{cm}^{3}$. Kalium merupakan salah satu logam alkali yang sangat reaktif, mudah teroksidasi di udara dan bereaksi hebat dengan air ${ }^{[211-215]}$. Di alam kalium sangat sedikit dan hanya 0,012\% dari kalium yang bersifat radioaktif. Unsur kalium adalah logam alkali yang lunak, berwarna putih keperakan yang, menghasilkan panas yang cukup untuk menyalakan hidrogen yang dipancarkan dalam reaksi dan terbakar dengan api berwarna ungu. kelarutan kalium dalam air laut ${ }^{[247]}$ sebesar $0,04 \%$ berdasarkan massa ${ }^{[201-205]}$ dan banyak ditemukan dalam mineral.

\section{$>$ Bromin}

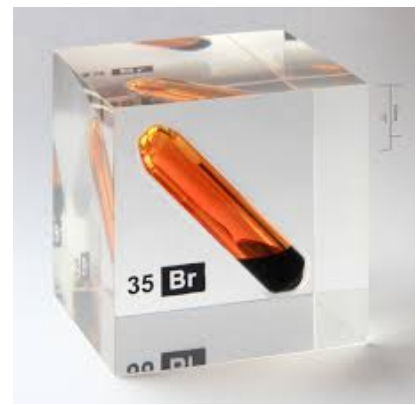

Gambar 6. unsur bromin

Sumber. https://id.wikipedia.org/wiki/Bromin

$\begin{array}{ll}\text { Jari-jari Bromin } & : 94 \mathrm{pm} \\ \text { Jari-jari kovalent } & : 120 \mathrm{pm} \\ \text { Jari - jari Van der Walls } & : 185 \mathrm{pm} \\ \text { Titik leleh } & :-7,3^{\circ} \mathrm{C} \\ \text { Titik didih } & : 59^{\circ} \mathrm{C}\end{array}$

Brom merupakan salah satu unsur ${ }^{[216-217]}$ dari golongan halogen dengan nomor atom 35. Unsur cair non logam ini memiliki warna kemerahan dan mudah menguap pada suhu kamar 
menghasilkan bau yang tajam, kereaktifannya berada di antara klor dan yodium. Unsur dengan nomor massa 79,904 ini memiliki sifat yang berat, mudah bergerak, menyerupai klor, dapat menyebabkan iritasi pada mata dan tenggorokan. Brom mudah larut dalam air atau karbon disulfida, membentuk larutan berwarna merah, keelektronegatifannya lebih rendah dari klor tapi lebih elektronegatif dari iod. Brom banyak digunakan dalam produksi etilen dibromida, komponen pembuatan bensin bersenyawa timbal ${ }^{[218]}$ yang anti-ketukan.

Sifat Fisika Kalium Bromida

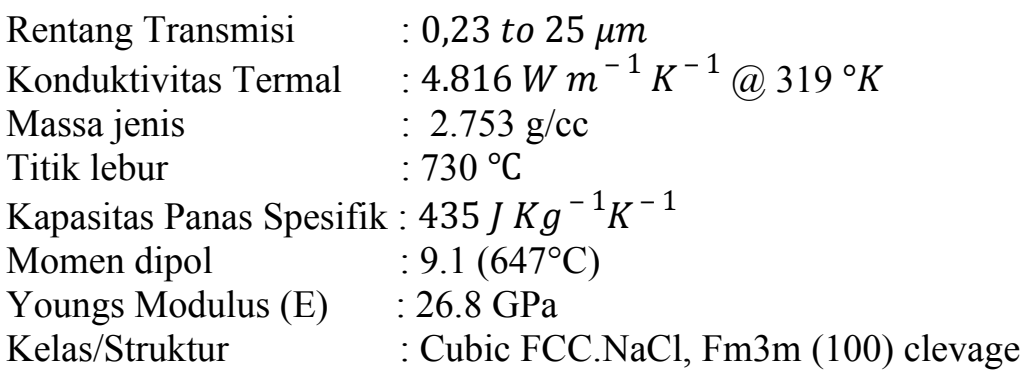

Sifat-sifat termokimia dari senyawa sesium klorida dalam fase liquid $\Delta_{f} H^{0}=-376,49 \mathrm{~kJ} / \mathrm{mol}$, $S^{0}=105,54 \mathrm{~J} / \mathrm{molK}, \Delta G^{0}=-378.8 \mathrm{~J} / \mathrm{molK}$, dan $\mathrm{C}_{\mathrm{p}}=52.07 \mathrm{~J} / \mathrm{molK}$

Beberapa pelarut yang dapat melarutkan kalium bromida

Tabel 1. Kelarutan kalium bromida dalam berbagai pelarut organik

\begin{tabular}{ccc}
\hline Pelarut & Temperatur ${ }^{\circ} \mathrm{C}$ & Kelarutan $(\mathrm{g} / 100 \mathrm{~g}$ of solvent $)$ \\
\hline 1- butanol & 20 & 0,0112 \\
Liquid amonia & $-33,9$ & 40,32 \\
Acetone & 18 & 0,00454 \\
Acetonitrile & 25 & 0,024 \\
Air & 25 & 68,1 \\
Duterium & 20 & 51,75 \\
Hydrazin & 20 & 60 \\
Hydroxylamine & 18 & 44,7 \\
Glycerol & 25 & 2,81 \\
Diethyl ether & 15 & 0,02
\end{tabular}

Sumber. http://chemister.ru/Database/properties-en.php?id=165

Kita dapat mengetahui dan memahami interaksi dan transpor dari suatu senyawa ionik (kalium bromida) melalui simulasi kemudian dengan memperhatikan pengaruh aspek termodinamika dari senyawa tersebut .

\subsection{Detail Simulasi}

Simulasi MD untuk KBr murni dilakukan di bawah kondisi tekanan 1 bar, pada sistem dengan 1024 pasangan $\mathrm{KBr}$, dengan waktu $\Delta \mathrm{t}=2$ fs. Untuk kalium bromida dalam air, simulasi telah dilakukan menggunakan 864 molekul dalam fase cair pada molalitas yang berbeda dan pada temperatur ${ }^{[206-210]} 298 \mathrm{~K}$ dan 1 bar tekanan. Konsentrasi molalitas diperoleh dari jumlah total ion dalam larutan $N_{\text {ions }}$, jumlah molekul air $N_{H 2 O}$ dan massa molar air $M_{H 2 O}$ sebagai:

$$
[K B r]=\frac{N_{\text {ions }} x 10^{3}}{2 N_{H 2 O} M_{H 2 O}}
$$

Pembagian dengan 2 persamaan ini menyumbangkan sepasang ion dan $M_{H 2 O}=18 \mathrm{~g} \mathrm{~mol}^{-1}$. Gambar 4 memberikan nilai molalitas untuk setiap titik perhitungan.

Perhitungan : 


$$
\begin{aligned}
& {[\mathrm{KBr}]=\frac{N_{\text {ions }} \times 10^{3}}{2 N_{H 2 O} M_{H 2 O}}} \\
& {[\mathrm{KBr}]=\frac{32 \times 10^{3}}{2 \times 832 \times 18}=0,99 \mathrm{~m}} \\
& {[\mathrm{KBr}]=\frac{58 \times 10^{3}}{2 \times 806 \times 18}=1,99 \mathrm{~m}} \\
& {[\mathrm{KBr}]=\frac{86 \times 10^{3}}{2 \times 778 \times 18}=3,07 \mathrm{~m}} \\
& {[\mathrm{KBr}]=\frac{110 \times 10^{3}}{2 \times 754 \times 18}=4,05 \mathrm{~m}} \\
& {[\mathrm{KBr}]=\frac{132 \times 10^{3}}{2 \times 732 \times 18}=5,0091 \mathrm{~m}}
\end{aligned}
$$

Tabel 2. Komposisi larutan KBr yang digunakan dalam simulasi pada suhu 298,15 K dan tekanan 1 bar.

\begin{tabular}{ccc}
\hline Molalitas $(\mathrm{m})$ & $N_{H 2 O}$ & $N_{\text {ions }}$ \\
\hline 0,99 & 832 & 32 \\
1,99 & 806 & 58 \\
3,07 & 778 & 86 \\
4,05 & 754 & 110 \\
5,0 & 732 & 132 \\
\hline
\end{tabular}

Sumber. https://arxiv.org/pdf/1611.02817.pdf

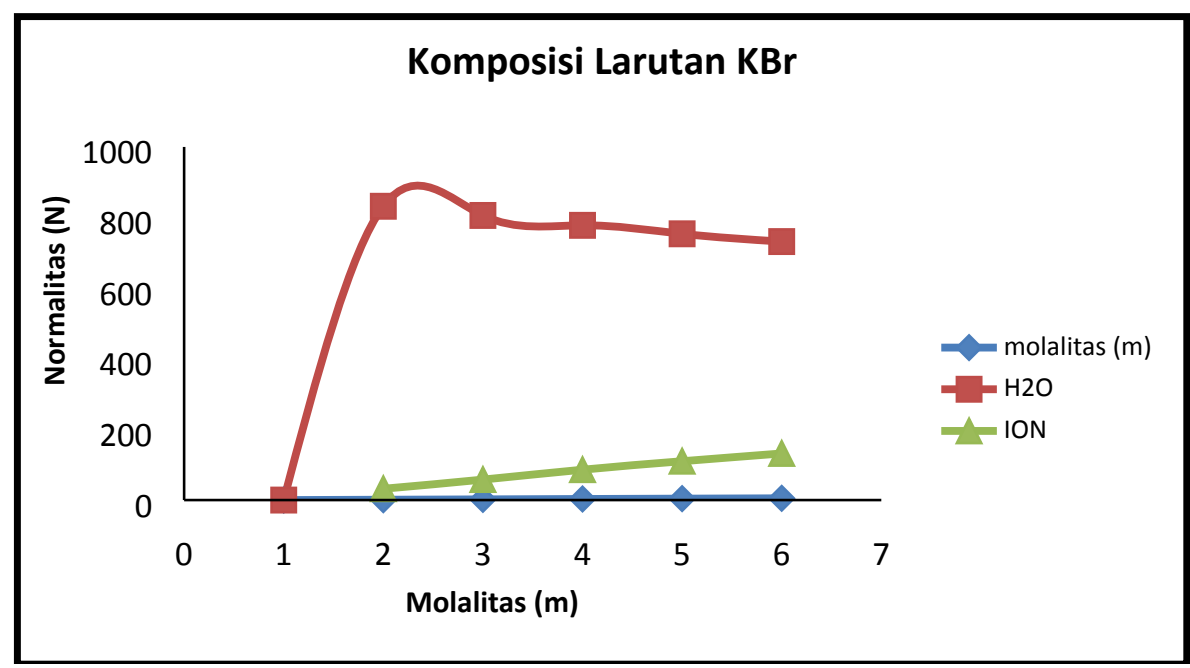

Gambar 6. Grafik Komposisi larutan KBr yang digunakan dalam simulasi pada suhu 298,15 K dan tekanan 1 bar.

\subsection{Model $\mathrm{KBr} / \varepsilon$}

Parameter untuk model $\mathrm{KBr} / \varepsilon$ dipilih untuk menghasilkan kembali kerapatan atau massa jenis kristal pada suhu $298 \mathrm{~K}$ dan tekanan 1 bar, dan untuk menunjukkan puncak dalam distribusi radial $^{(41-50)}$ sesuai dengan eksperimen yaitu $2,74 \mathrm{~g} \mathrm{~cm}^{-318}$. 
Tabel 4 menunjukkan perbandingan nilai yang diperoleh untuk densitas(kerapatan), Energi Kisi dan Kisi Kristal untuk model $\mathrm{KBr} / \varepsilon$, untuk eksperimen, Joung Cheatham, medan gaya JC, dan untuk medan gaya parametrized dengan $\mathrm{SPC} / \mathrm{E}$ air, model $\mathrm{JC}_{\mathrm{S} 3}$.

Tabel 3. Kepadatan KBr pada tekanan 1 bar dan suhu 298 K, Energy Kisi, kisi kristal dari berbagai medan gaya dan untuk experiment

\begin{tabular}{cccc}
\hline Model Ions & $\rho /\left(\mathrm{g} / \mathrm{cm}^{3}\right)$ & $\mathrm{LC} / \AA$ & $\mathrm{LE} /(\mathrm{kJ} / \mathrm{mol})$ \\
\hline$J C_{S 3}$ & 2,61 & 6,66 & 695,38 \\
$J C_{T 4}$ & 2,67 & 6,62 & 698,72 \\
$\mathrm{KBr}$ & 2,76 & 6,58 & 582,9 \\
experimental & 2,74 & 6,6 & 671,11 \\
\hline Sumer.
\end{tabular}

Sumber. https://arxiv.org/pdf/1611.02817.pdf

$\mathrm{KBr} / \varepsilon$, untuk model $\mathrm{JC}_{\mathrm{S} 3}$ dan $\mathrm{JC}_{\mathrm{T} 4}$, hasilnya konsisten hal ini membuktikan bahwa model yang digunakan sebagai parameter memberikan nilai kerapatan atau densitas yang benar.

Selain sifat termodinamika, transportasi juga dinilai. Menggeser viskositas $\eta$ pada konsentrasi molal yang berbeda pada tekanan 1 bar dan suhu $298 \mathrm{~K}$. Gambar 7 mengilustrasikan viskositas versus konsentrasi molal dari garam menunjukkan peningkatan $\eta$ karena konsentrasi garam yang menyatakan bahwa sistem menjadi lebih kental. Hasil ini konsisten dengan nilai eksperimental, untuk konsentrasi encer juga ditunjukkan pada gambar yang sama.

Tabel 4. Viskositas versus konsentrasi molal dari garam dalam beberapa model

\begin{tabular}{cccc}
\hline \multirow{2}{*}{$\begin{array}{c}\text { Konsentrasi } \\
\left(\mathrm{m} / \mathrm{mol} \mathrm{kg}^{-1}\right)\end{array}$} & \multicolumn{3}{c}{ Viskositas (mPas) untuk Model Ion } \\
\cline { 2 - 4 } & $\mathrm{TIP} / \mathrm{Ew}+\mathrm{KBr}-J C_{T 4}$ & $\mathrm{SPC} / \mathrm{E}+\mathrm{KBr}-J C_{S 3}$ & $\mathrm{TIP} 4 \mathrm{P} / \varepsilon+K B r / \varepsilon$ \\
\hline 0 & 0,75 & 0,78 & 0,85 \\
1 & 0,87 & 0,74 & 0,88 \\
2 & 0,96 & 0,89 & 0,96 \\
3 & 1,05 & 0,98 & 0,99 \\
\hline
\end{tabular}

Sumber. https://arxiv.org/pdf/1611.02817.pdf

\section{Viskositas terhadap konsentrasi molal garam pada suhu} 298 K dan tekanan 1 bar.

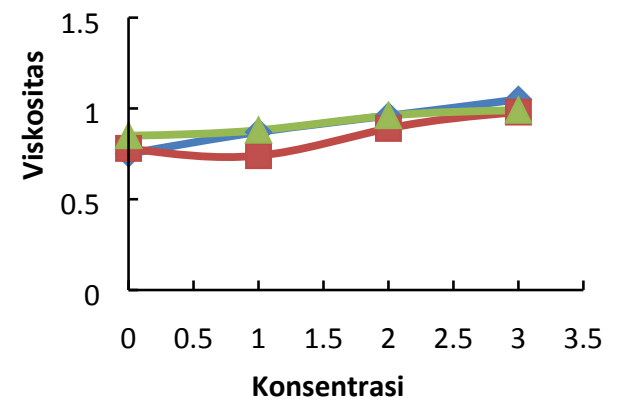

Viskositas (mPas) untuk Model Ion TIP4P/Ew + KBr-

- Viskositas (mPas) untuk Model Ion SPC/E +KBr-

Viskositas (mPas) untuk Model Ion TIP4P/

Gambar 7. Viskositas terhadap konsentrasi molal garam pada suhu $298 \mathrm{~K}$ dan tekanan 1 bar. Garis hitam adalah data eksperimental dan garis biru adalah hasil untuk model yang digunakan.

Tabel 5. Tingkat kekentalan atau viskositas larutan kalium bromida dalam berbagai temperatur.

Temperatur ${ }^{\circ} \mathrm{C} \quad$ Viskositas $(\mathrm{mPa} \cdot \mathrm{s})$

\begin{tabular}{ll}
\hline 747 & 1,18 \\
847 & 0,92 \\
907 & 0,83 \\
\hline
\end{tabular}


Perhitungan viskositas :

Speed sound $(\mathrm{m} / \mathrm{s}): 1770\left(747^{\circ} \mathrm{C}\right.$, aggregative state - liquid $)$

$\rho$ air $=1,00\left(25^{\circ} \mathrm{C}, \mathrm{g} / \mathrm{cm}^{3}\right)$

$\rho K B r=2,75\left(25^{\circ} \mathrm{C}, \mathrm{g} / \mathrm{cm}^{3}\right)$

Radius of $\mathrm{K}^{+}=133 \mathrm{pm}$

Radius of $\mathrm{Br}^{-}=196 \mathrm{pm}$

Radius Ratio $=133 / 196=0.678$

$$
\eta=\frac{2 r^{2} g}{9 v}(\rho K B r-\rho \text { air })
$$

$\eta=\frac{2.0,678^{2} 10 \mathrm{~kg} / \mathrm{m}^{3}}{9.1770 \mathrm{~m} / \mathrm{s}} 2750 \mathrm{~kg} / \mathrm{m}^{3}-1000 \mathrm{~kg} / \mathrm{m}^{3}$

$\eta=\frac{9,19368 \mathrm{~kg} / \mathrm{m}^{3}}{15.930 \mathrm{~m} / \mathrm{s}} 1750 \mathrm{~kg} / \mathrm{m}^{3}$

$\eta=1,1 m P a . s$

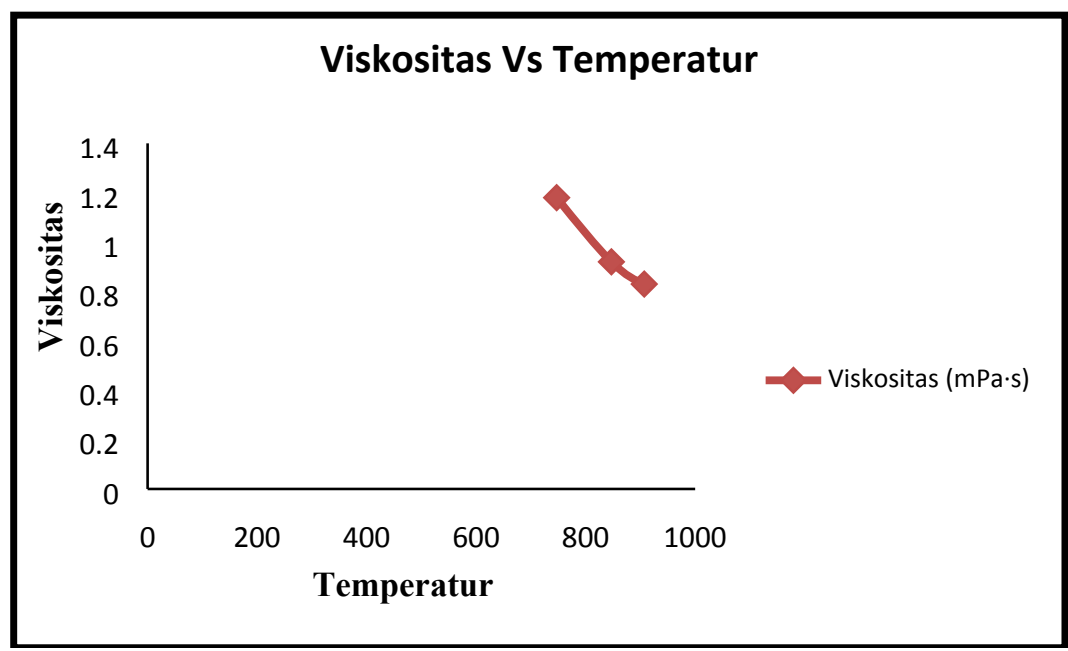

Gambar 8. Tingkat kekentalan atau viskositas larutan kalium bromida dalam berbagai temperatur.

Dari gambar terlihat semakin tinggi temperatur suatu larutan kalium bromida maka tingkat viskositas atau kekentalannya akan semakin rendah. Hal ini dikarenakan pada temperatur yang tinggi energi kinetik dari ion-ion pada larutan kalium bromida akan semakin besar sehingga ikatan atau gaya ikat antar ion atau molekul menjadi sangat rendah sehingga tingkat viskositas atau kekentalannya pun menurun.

Tabel 6. Tingkat kelarutan kalium bromida dalam air pada temperatur tertentu

\begin{tabular}{cc}
\hline Temperatur ${ }^{\circ} \mathrm{C}$ & Kelarutan $(\mathrm{g} / 100$ g pelarut $)$ \\
\hline 0 & 53,5 \\
10 & 59,5 \\
20 & 65,2 \\
25 & 68,1 \\
30 & 70,9 \\
40 & 75,8 \\
60 & 85,5 \\
80 & 94,6 \\
100 & 103,3
\end{tabular}


Sumber. http://chemister.ru/Database/properties-en.php?id=165

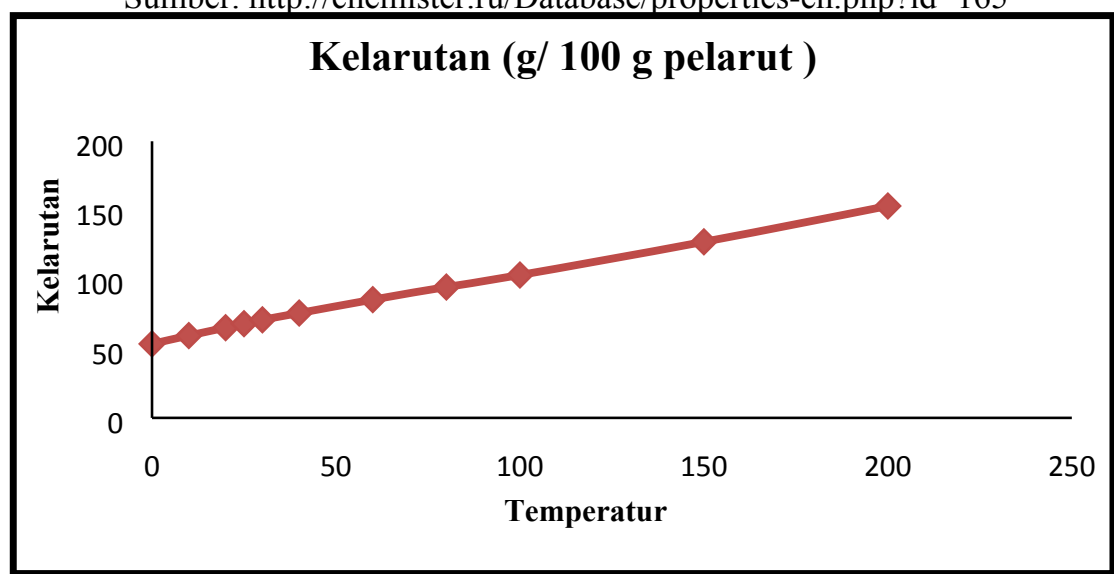

Gambar 9. Tingkat kelarutan kalium bromida dalam air pada temperatur tertentu

Kapasitas Panas Fase ${ }^{(51-55)}$ Gas (Persamaan Shomate)

$\mathrm{Cp}=$ kapasitas panas $\left(\mathrm{J} / \mathrm{mol}^{0} \mathrm{~K}\right)$

$\mathrm{H}^{\circ}=$ entalpi standar $(\mathrm{kJ} / \mathrm{mol})$

$\mathrm{S}^{\circ}=$ entropi standar $\left(\mathrm{J} / \mathrm{mol}^{0} \mathrm{~K}\right)$

$\mathrm{T}=\operatorname{suhu}(\mathrm{K}) / 1000$.

Energi ${ }^{(56-60)}$ Bebas $(\Delta G)$ Kalium Bromida

$$
\Delta G=\Delta H-T \Delta S
$$

Perhitungan :

$\Delta G^{0}=\Delta H^{0}-T \Delta S^{0}$

Untuk T 2500

$\Delta G=84,61-2500 \times 331,5$

$\Delta G=84,61-828.750$

$\Delta G=-828.665,39$ (Spontan)

Untuk T 2600

$\Delta G=84,61-2600 \times 331,5$

$\Delta G=84,61-861.900$

$\Delta G=-861.815,39$ (Spontan)

Semakin meningkat temperatur maka semakin besar perubahan energi bebasnya ( energi gibbs/ $\Delta G$ ) semakin spontan reaksi yang terjadi

Tabel 7. Kapasitas Panas Fase Gas untuk berbagai temperatur

\begin{tabular}{ccccc}
\hline $\begin{array}{c}\text { Temperature } \\
(\mathbf{K})\end{array}$ & $\begin{array}{c}\mathbf{C}_{\mathbf{p}} \\
(\mathbf{J} / \mathbf{m o l} \mathbf{K})\end{array}$ & $\begin{array}{c}\mathbf{S}^{\circ} \\
\left(\mathbf{J} / \mathbf{m o l}{ }^{*} \mathbf{K}\right)\end{array}$ & $\begin{array}{c}-\left(\mathbf{G}^{\circ}-\mathbf{H}^{\circ}{ }_{\mathbf{2 9 8 . 1 5}}\right) / \mathbf{T} \\
(\mathbf{J} / \mathbf{m o l} \mathbf{K})\end{array}$ & $\begin{array}{c}\mathbf{H}^{\circ}-\mathbf{H}^{\circ}{ }_{298.15} \\
(\mathbf{k J} \mathbf{m o l})\end{array}$ \\
\hline 2500. & 39.38 & 331.5 & 297.6 & 84.61 \\
2600. & 39.46 & 333.0 & 298.9 & 88.56 \\
2700. & 39.54 & 334.5 & 300.2 & 92.51 \\
2800. & 39.62 & 335.9 & 301.5 & 96.46 \\
2900. & 39.70 & 337.3 & 302.7 & 100.4 \\
3000. & 39.77 & 338.7 & 303.9 & 104.4 \\
3100. & 39.85 & 340.0 & 305.0 & 108.4 \\
3200. & 39.93 & 341.2 & 306.1 & 112.4 \\
3300. & 40.01 & 342.5 & 307.2 & 116.4 \\
\hline
\end{tabular}




$$
3400 .
$$

$$
40.09
$$

343.7

308.3

120.4

https://webbook.nist.gov/cgi/cbook.cgi?ID=C7758023\&Mask=1\&Type=JANAFG\&Table=on

Berdasarkan tabel diatas, terlihat dengan adanya peningkatan temperatur mengakibatkan kapasitas panas, entropi ${ }^{(61-65)}$ standar, dan perubahan entalpi ${ }^{(66-70)}$ standar meningkat. Semakin tinggi temperatur maka entropi atau ketidakteraturan suatu atom dalam senyawa/molekul[ ${ }^{[227-232]}$ semakin tinggi. Hal ini dikarenakan pergerakan ion dalam senyawa $\mathrm{KBr}$ semakin besar sehingga ketidakteraturannya semakin tinggi.

\subsection{Gerakan Ion}

Dalam menentukan pengukuran konduktivitas, terlebih dahulu mengetahui penyebab dari pergerakan ion dengan laju yang berbeda-beda, dan penyebab ion tersebut memiliki konduktivitas molar yang berlainan, serta sebab konduktivitas molar elektrolit kuat berkurang dengan akar konsentrasi.

Konsep nya adalah: makin besar mobilitas ion dalam larutan,maka makin besar pula kontribusinya pada konduktivitas (untuk muatan tertentu).

\subsubsection{Kecepatan hanyut (s)}

Jika dua elektroda yang terpisah dengan jarak 1 berada pada selisih potensial ${ }^{(71-80)}(\Delta \emptyset)$, maka ion dalam larutan diantara kedua elektroda tersebut, mengalami medan listrik (E) sebesar :

$$
E=\frac{\Delta \emptyset}{l}
$$

Untuk ion ze (muatan ion) mengalami gaya sebesar :

$$
F=z e E=\frac{z e \Delta \emptyset}{l}
$$

Sedangkan gaya perlambatan (F'), sedangkan gaya gesek ${ }^{(81-90)}$ (f) maka :

$$
F^{\prime}=f s \quad(10) \quad f=6 \pi \eta a \quad(6)
$$

Kedua gaya ini bekerja dalam arah yang berlawanan dan ion mencapai kecepatan akhir, yaitu kecepatan hanyut ion (s), jika gaya mempercepat $\mathrm{F}$ diimbangi oleh gaya perlambatan $\mathrm{F}^{\prime}$. Gaya neto ${ }^{(91-}$ 95) menjadi nol $\left(\mathrm{F}=\mathrm{F}^{\prime}\right)$ jika :

$$
s=\frac{z e E}{f}
$$

Perhitungan kecepatan hanyut :

Pemisalan Jika potensial $\mathrm{KBr} 8.34 \mathrm{~V}$ dan jarak antara elektroda adalah $4 \mathrm{~cm}$, maka kecepatan hanyutnya dapat dihitung sebagai berikut :

$$
\begin{aligned}
& E=\frac{\Delta \emptyset}{l} \\
& E=\frac{8.34 \mathrm{~V}}{4 \mathrm{~cm}}=2,085 \mathrm{~V} / \mathrm{cm}
\end{aligned}
$$

Jadi kecepatan hanyut $\mathrm{KBr}$ adalah 2,085 $\mathrm{V} / \mathrm{cm}$

\subsubsection{Mobilitas ion (U)}

Mobilitas ion dapat dihitung dengan pengukuran sebenarnya jarak ${ }^{(96-105)}$ yang ditempuh setiap ion ${ }^{[219]}$ dalam waktu tertentu dengan metode batas bergerak.

$\mathrm{x}=\operatorname{jarak}(\mathrm{m})$

$$
U=\frac{x}{t\left(\frac{d E}{d x}\right)}
$$

$\mathrm{t}=$ waktu (dt) 
$\left(\frac{d E}{d x}\right)=$ kekuatan medan $\left(\right.$ volt. $\left.\mathrm{m}^{-1}\right)$

$$
E=\frac{d E}{d x}=\frac{I}{A L_{S}}
$$

Maka

$\mathrm{Z}=$ valensi $^{(106-115)}$ kation

$$
U=\frac{\lambda_{m}}{z F}
$$

$\mathrm{F}=$ Faraday

Tabel 9. Data mobilitas relative ion kalium dan bromin

\begin{tabular}{ccccc} 
& Ion & Nama ion & Valensi & Mobilitas relative \\
\cline { 2 - 4 } & & & \\
\hline & $\mathrm{K}^{+}$ & Potassium & 1 & 1,000 \\
$\mathrm{Br}^{-}$ & Bromide & -1 & 1,063 \\
\hline
\end{tabular}

$$
t_{+}=\frac{U_{+}}{U_{+}+U_{-}} \quad \text { (11) } \quad u=\frac{s}{E}
$$

Jika larutan elektrolit kuat pada konsentrasi molar (c) menimbulkan $v_{+}$kation dengan muatan $z_{+}$

$$
J(\text { ion })=\frac{s \Delta t A x v c N_{A}}{A \Delta t}=s v c N_{A}
$$

setiap ion membawa muatan $z e$ sehingga fluks muatan ${ }^{(106 ; 108 ; 110 ; 116-122)}$ adalah :

$$
J(\text { muatan })=z s v c e N_{A}=z s v c F
$$

Dengan $F=e N_{A}$ merupakan konstanta Faraday ${ }^{(113 ; 115 ; 123-128)}$ dan $s=u E$ maka fluksnya

$$
J(\text { muatan })=z u v c F
$$

Maka arus I : fluks muatan x luas

$$
I=J A=z u v c F A E
$$

Karena medan listrik merupakan gradien potensial $\Delta \phi / l$ maka

$$
\begin{gathered}
I=\frac{z u v c F A \Delta \emptyset}{l} \\
I=\frac{\Delta \emptyset}{R}=\frac{L_{s} A \Delta \emptyset}{l}
\end{gathered}
$$

Atau $L_{S}=z u v c F$

Untuk larutan dalam limit konsentrasi nol :

$$
\Lambda_{m}^{0}=\left(z_{+} u_{+} v_{+}+z_{-} u_{-} v_{-}\right) F
$$

untuk elektrolit simetris $\mathrm{z}: \mathrm{z}$ (misalnya $\mathrm{CuSO}_{4}$ ) maka

$$
\Lambda_{m}^{0}=z\left(u_{+}+u_{-}\right) F
$$

Tabel 10 . Koefisien Difusi ${ }^{(129-138)} \mathrm{D}$ dan Mobilitas u dari KBr pada Pengenceran Tak Terbatas Air pada suhu $25^{\circ} \mathrm{C}$ Dihitung dari Mean Square Fungsi Displacements dan Velocity Autocorrelation

\begin{tabular}{ccccc}
\hline \multirow{2}{*}{ Ion } & \multicolumn{2}{c}{$\mathrm{D}\left(\mathrm{x} 10^{-2} \mathrm{~cm}^{2} / \mathrm{s}\right)$} & \multicolumn{2}{c}{$\mathrm{U}\left(\mathrm{x} 10^{-4} \mathrm{~cm}^{2} / \mathrm{Vs}\right)$} \\
\cline { 2 - 5 } & $\mathrm{MSD}$ & $\mathrm{VAC}$ & $\mathrm{MSD}$ & $\mathrm{VAC}$ \\
\hline $\mathrm{Br}^{-}$ & $1,89 \pm 0,24$ & $1,87 \pm 0,22$ & $7,35 \pm 0,93$ & $7,27 \pm 0,86$ \\
$\mathrm{~K}^{+}$ & $2,02 \pm 0,45$ & $2,17 \pm 0,42$ & $7,86 \pm 1,75$ & $8,45 \pm 1,63$ \\
\hline
\end{tabular}


Harga mobilitas ion mempengaruhi nilai konduktivitas dari suatu senyawa, semakin besar tingkat mobilitas ion dalam larutan maka semakin besar pula pengaruhnya konduktivitas ion dalam hal ini konduktivitas ion dalam senyawa kalium bromida

\subsubsection{Bilangan transport (t)}

\section{Definisi :}

Fraksi dari arus total yang dibawa oleh ion jenis tertentu. Untuk larutan dengan 2 jenis ion, bilangan transport kation :

$$
\begin{array}{lc}
t_{+}=\frac{I^{+}}{I} & \mathrm{I}=\text { arus total } \\
I=t_{+}+t_{+} & \text {(21) }
\end{array}
$$

Bilangan transport pembatas $\left(\mathrm{t}^{0}\right)$ untuk limit konsentrasi nol dari larutan elektrolit ${ }^{[254] .}$

Jika $I \infty K$ sehingga :

$$
t^{0}=\frac{z v u}{\sum_{i} z v u_{i}}
$$

Untuk elektrolit simetris (bilangan muatan untuk kedua ion sama) maka persamaan diatas disederhanakan :

$t^{0}=\frac{u}{\sum_{i} u_{i}}$

Hubungan antara konduktivitas ion dengan mobilitas ${ }^{(107 ; 109 ; 139-144)}$ ion :

$t^{0}=\frac{v \lambda}{\sum_{i} v_{i} \lambda_{i}}=\frac{v \lambda}{\Lambda^{0}{ }_{m}}$

Jadi untuk setiap jenis ion :

$$
v \lambda=t^{0} \Lambda_{m}^{0}
$$

Penentuan bilangan transport :

\section{a. Metode Hittorf}

Prinsip : Menentukan perubahan konsentrasi ${ }^{[251-252]}$ elektrolit disekitar elektroda yang disebabkan karena migrasi ion.

Sel Hittorf : seperangkat alat elektrolisis yang terdiri atas pesawat Hittorf ${ }^{(145-152)}$, sepasang elektroda, dan sumber tegangan arus searah

\section{b . Metode Perbatasan gerak}

Transmitansi sampel $\mathrm{KBr}$ dalam rentang spektrum UV-VIS.

\subsubsection{Hantaran Ion}

untuk menghitung hantaran molar ion pada pengenceran tidak berhingga dapat menggunakan persamaan :

$$
\begin{aligned}
& v^{+} \lambda^{0+}=\left(t_{+}\right)^{0} \Lambda \\
& v^{-} \lambda^{0-}=\left(t_{-}\right)^{0} \Lambda
\end{aligned}
$$

Dimana $\quad\left(t_{+}\right)^{0}=$ bilangan transport ion sampai pengenceran tak hingga

$\left(v^{+}\right)=$jumlah ion yang muatan positif 


\subsubsection{Konduktivitas}

\subsubsection{Konduktivitas Listrik dari Larutan Berair}

Adapun Tabel berikut menunjukkan konduktivitas listrik berair larutan $\mathrm{KBr}$ sebagai fungsi konsentrasi. Semua nilai mengacu pada suhu $20^{\circ} \mathrm{C}$. Konduktivitas $\kappa$ atau yang sering disebut konduktansi spesifik dalam literatur lama adalah kebalikan dari resistivitas $\left.{ }^{(111 ;} 114 ; 153-158\right)$. Konduktivitas molar $\Lambda$ terkait dengan ini oleh $\Lambda=\kappa / \mathrm{c}$, dimana c adalah konsentrasi jumlah zat elektrolit.

Jadi jika $\kappa$ memiliki satuan milisiemens per sentimeter $(\mathrm{mS} / \mathrm{cm})$, seperti pada tabel ini, dan $\mathrm{c}$ dinyatakan dalam mol / L, maka $\Lambda$ memiliki satuan $\mathrm{S} \mathrm{cm}^{2} \mathrm{~mol}^{-1}$. Untuk elektrolit ini, konsentrasi c yang sesuai dirubah ke nilai persen massa, berikut data nya :

Tabel 11. Konduktivitas Listrik $\kappa$ dalam $\mathrm{mS} / \mathrm{cm}$ untuk Konsentrasi Indikasi

\begin{tabular}{ccc}
\multicolumn{3}{c}{ dalam Persen Massa } \\
\hline No & Persen massa & Konduktivitas listrik (Ms/cm) \\
\hline 1 & $0,5 \%$ & 5,2 \\
2 & $1 \%$ & 10,2 \\
3 & $2 \%$ & 19,5 \\
4 & $5 \%$ & 47,7 \\
5 & $10 \%$ & 95,6 \\
6 & $15 \%$ & 144 \\
7 & $20 \%$ & 194 \\
\hline
\end{tabular}

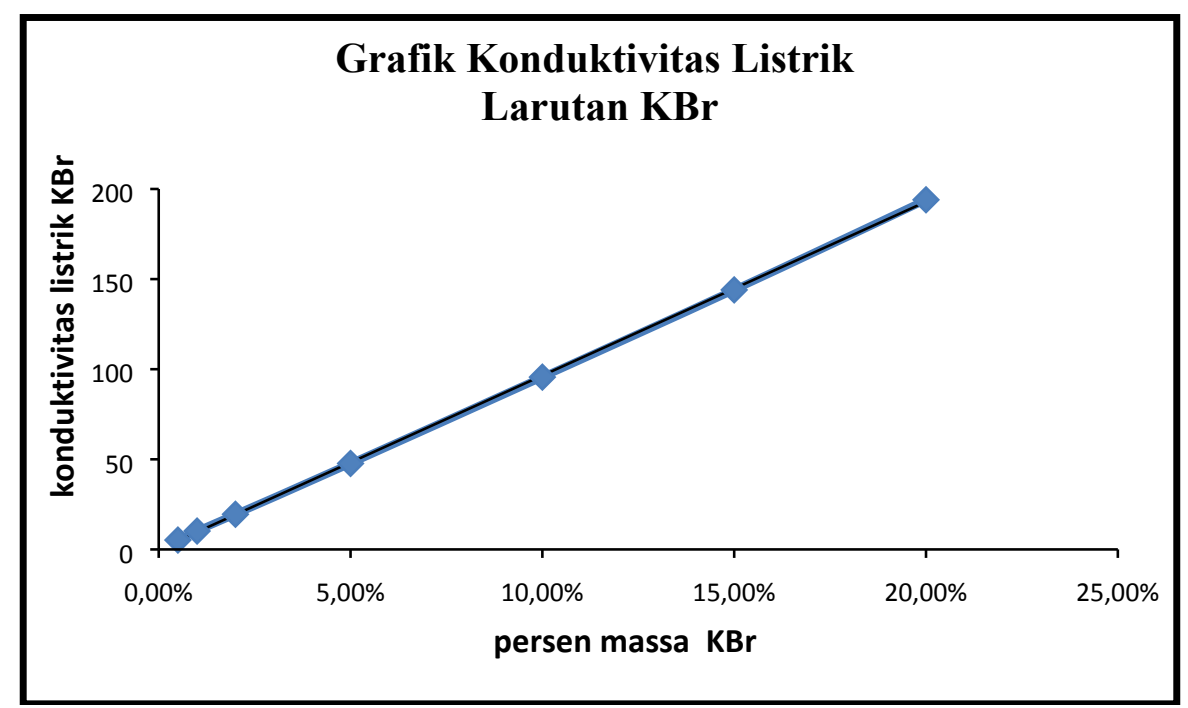

Gambar 7. Konduktivitas Listrik $\kappa$ dalam $\mathrm{mS} / \mathrm{cm}$ untuk Konsentrasi Indikasi dalam Persen Massa ${ }^{(159-163)}$

Perhitungan konduktivitas molar $\Lambda$ :

$$
\Lambda=\frac{\kappa}{c}
$$

Diketahui untuk persen massa 0,5\% dan konduktifitas listrik 5,2, maka konduktivitas molar dapat ditentukan dengan persamaan :

$$
\begin{aligned}
& \Lambda=\frac{\kappa}{c} \\
& \Lambda=\frac{5,2}{0,5} \\
& \Lambda=10,4 \quad \mathrm{~S} \mathrm{~cm}^{2} \% \text { massa }
\end{aligned}
$$




\subsubsection{Konduktivitas Thermal}

Konduktivitas termal adalah ukuran atau kemampuan suatu material atau bahan untuk menghantarkan energi. Energi termal dapat dihantarkan dalam zat ${ }^{[233-238]}$ padat melalui getaran kisi elektron bebes. Untuk konduktor yang baik, elektron bergerak bebas didalam struktur kisi material, maka, selain dapat mengangkut muatan listrik elektron dapat membawa energi ${ }^{[253]}$ termal dari yang bertemperatur tinggi ke daerah dengan temperatur rendah.

Konduktivitas atau keterhantaran termal,k, merupakan suatu besaran intensif material yang mampu untuk menghantarkan panas. Konduksi termal merupakan suatu bentuk transport di mana perbedaan temperatur yang menyebabkan terjadinya transfer energi termal dari satu wilayah dengan temperatur tinggi ke wilayah dengan temperatur yang lebih. Panas yang di pindahkan dari satu titik ke titik lain melalui salah satu dari tiga metode yaitu konduksi, konveksi, dan radiasi.

$$
k=\frac{Q}{t} x \frac{L}{A x \Delta T}
$$

Konduktivitas termal dapat didefinisikan sebagai panas atau kalor, Q, yang dihantarkan selama waktu $t$ melalui ketebalan $\mathrm{L}$, dengan arah normal ke permukaan dengan luas A yang disebabkan oleh perbedaan suhu $\Delta \mathrm{T}$ (temperatur) dalam kondisi tunak dan jika perpindahan panas hanya tergantung dengan perbedaan suhu tersebut.

\subsubsection{Konduktivitas Ionik}

Konduktivitas ionik merupakan salah satu cara untuk mengukur kemampuan suatu partikel ${ }^{[239-245]}$ bermuatan (ion) untuk bergerak melalui struktur kristal ${ }^{(164-168)}$ material. Elektrolit adalah senyawa dan unsur yang mampu menerima pergerakan ion melalui strukturnya biasanya dalam bentuk padat atau cair.

Hukum pertama Fick tentang difusi

Andaikan fluks pertikel yang berdifusi, merupakan gerakan sebagai reaksi terhadap gaya termodinamika yang timbul dari gradient konsentrasi. Partikel akan mencapai kecepatan hanyut tetap $s$ jika gaya termodinamika $f$ sama dengan tahan kental.kecepatan ${ }^{(169-173)}$ hanyut ini sebanding dengan gaya termodinamika, dan kita tuliskan $s \propto f$. Akan tetapi, fluks partikel $J$ sebanding dengan kecepatan hanyut, dan gaya termodinamika sebanding dengan gradient konsentrasi $d c / d x$. Rantai kesebandingan itu $(J \propto s, s \propto f$, dan $f \propto d c / d x$ menunjukkan bahwa:

$$
J \propto \frac{d c}{d x}
$$

Yang merupakan kandungan hokum Fick

\section{Aplikasi}

\subsection{Makanan}

$\mathrm{KBr}$ merupakan garam yang digunakan sebagai antikonvulsan. Kalium ${ }^{(174-179)}$ bromida dapat digunakan untuk membuat perak bromida. Kalium bromida dilarang di banyak negara untuk dijadikan campuran makanan sebagai zat pemberi rasa pada makanan. Kalium bromida adalah zat pengoksidasi $i^{(180-184)}$ dan dapat digunakan untuk memanggang roti agar memperkuat adonan dan merupakan elektrolit yang kuat.

\subsection{Medis dan kedokteran hewan}

Pada 1857 dalam Royal Medical and Chirurgical Society London, Sir Charles Locock menemukan sifat antikonvulsan dan obat ${ }^{(112 ; 185-188)}$ penenang potasium bromida ${ }^{(189-192)}$ dan mulai mengobati pasiennya. Bromida dapat dianggap sebagai obat efektif pertama untuk epilepsi yang diduga disebabkan oleh masturbasi..$^{[3]}$ Dari titik itu, kalium bromida menjadi pengobatan pilihan untuk manusia dengan serangan epilepsi dan gangguan saraf sampai penemuan tahun 1912 dari Phenobarbital. 
Pengenalan Phenobarbital sangat menurunkan popularitas dari kalium bromida dalam kegunaanya mengobati manusia dari serangan epilepsi. Akibatnya, kalium bromida tidak disetujui oleh Administrasi Makanan dan Obat AS.

Phenobarbital adalah obat dengan fungsi untuk mengendalikan kejang-kejang. Akan tetapi karena penggunaan yang berlebihan dapat menimbulkan efek samping yang berbahaya yaitu pasien dapat mengalami reaksi sakaw, terutama jika penggunaan yang teratur dalam jangka waktu yang lama atau dalam dosis yang tinggi. Gejala sakaw yang terjadi antara lain seperti halusinasi, berkedut, atau kesulitan tidur. Solusi dari masalah ini adalah dengan penggunaan yang sesuai dengan dosis dokter, konsultasikan dengan dokter atau apoteker untuk setiap penggunaan serta melaporkan setiap reaksi penolakan yang terjadi sesegera mungkin.

[5] Waktu paruh bromida yang sangat lama di dalam tubuh sehingga menyebabkan timbulnya efek samping. Penggunaan medis bromida di Amerika Serikat dihentikan karena banyak obat penenang lain yang lebih baik dan lebih pendek waktu paruhnya.

Kalium bromida digunakan dalam pengobatan hewan untuk mengobati epilepsi pada anjing, Penggunaan bromida pada kucing terbatas karena mengandung risiko yang besar yaitu dapat menyebabkan terjadinya radang paru-paru (pneumonitis).

\subsection{Optika}

Senyawa kalium bromida dapat digunakan secara luas sebagai jendela optik inframerah dan komponen untuk spektroskopi umum karena jangkauan spektrumnya yang lebar. Kalium bromida bersifat transparan dari panjang gelombang ultraviolet sampai gelombang panjang inframerah (0.25$25 \mu \mathrm{m}$ ) dan tidak memiliki garis absorpsi optis yang signifikan pada rentang transmisinya yang tinggi.

Dalam spektroskopi inframerah, sampel dapat dianalisis dengan cara menggerus sampel dengan bubuk kalium bromida kemudian menekan bubuk ke dalam cakram. Untuk alternatif, sampel tersebut dapat dianalisis sebagai film cair (sebagai larutan, atau dalam mull dengan Nujol) antara dua cakram kalium bromida yang dipoles. ${ }^{[6]}$

Senyawa kalium bromida harus disimpan dalam lingkungan yang kering karena kelarutan dan keadaan higroskopisnya yang tinggi dengan indeks bias sekitar 1.55 pada $1.0 \mu \mathrm{m}$.

\subsection{Fotografi}

Selain pembuatan perak bromida, kalium bromida juga dapat digunakan sebagai penghambat pada pengembangan formula fotografi hitam putih. Penambahan senyawa ini meningkatkan diferensiasi antara kristal terbuka dan tidak terpisahkan dari halida perak, dan dengan demikian dapat mengurangi timbulnya kabut.

\section{Kesimpulan}

Senyawa ionik kalium bromida mengalami interaksi antar ion dalam sistem larutan, baik antara sesama ion maupun dengan ion yang yang lain, transportasi ion dan interaksi ion sangat di pengaruhi oleh aspek termodinamika senyawa tersebut. Hal ini dapat dilihat dari kelarutannya dalam air: $68,1 / 100 \mathrm{~g}$ air pada suhu $273^{\circ} \mathrm{K}$; energi gibbs: $\Delta G^{0}=-378.8 \mathrm{~J} / \mathrm{molK}$; kecepatan hayutnya: 2,085 V/cm, konduktivitasnya (konduktivitas listrik: $5,2 \mathrm{Ms} / \mathrm{cm}$ untuk persen massa $0,5 \%$ ); tingkat viskositasnya: $1,18 \mathrm{mPa} \cdot \mathrm{s}$ pada suhu $747^{\circ} \mathrm{C}$; mobilitas relative ion $\mathrm{K}^{+}$dan $\mathrm{Br}^{-}$adalah 1,000 dan 1,063 serta berbagai sifat termodinamika lainnya. Massa molar : 119,00 $\mathrm{g} / \mathrm{mol}$; Penampilan: fasa padat berupa bubuk kristal putih; Densitas : $2.753 \mathrm{~g} / \mathrm{cc}$; Titik lebur: $730^{\circ} \mathrm{C}$.

\section{Referensi:}

1. Ion DC. 1976. Availability of world energy resources : 1. supplement: coal, nuclear energy, natural gas. London: Graham \& Trotman. 104 s. pp.

2. Ion DC. 1978. Availability of world energy resources : second supplement. London: Graham \& Trotman. 112 s. pp.

3. The Rumanian Communist Party. Congress : 1965 (9.., Maurer IG, Stoica C, Apostol G. 1965. Report on the directives of the ninth congress of the Rumanian Communist Partry on 
the plan for the development of the national economy in the 1966-1970 period: july 20, 1965. Bucharest,: Agerpres. 104 s. pp.

4. Schreyer P, OECD. Directorate for Science Technology and Industry. 2000. High-growth firms and employment. Paris: Organisation for Economic Co-operation and Development. 48 s. pp.

5. OECD. Directorate for Science Technology and Industry. Committee on Consumer Policy. 1999. Online advertising and marketing directed toward children. Paris: OECD. 43 s. pp.

6. World Bank. Africa Technical Department. Industry and Energy Division. Mining Unit. 1992. Strategy for African mining. Washington, D.C.: World Bank. xiv, 79 s. pp.

7. Amaro A, Reed D, Soares P, ProQuest (Firm). 2003. Modelling forest systems. Wallingford, Oxon, UK ; Cambridge, MA: CABI Pub.

8. International Conference on Control of Distributed Parameter Systems (4 : 1988 : Vorau)., Kappel F, Kunisch K, Schappacher W. 1989. Control and estimation of distributed parameter systems : 4th International Conference on Control of Distributed Parameter Systems, Vorau, July 10-16, 1988. Basel: Birkhäuser. xiii, 434 s. pp.

9. Smudge, Quantum, Solo E, Ol' Dirty B, Parameter 2., Prisoners of Technology. 2000. Jumpuptouchdown. London: Lacerba. 3 cd'er + pp.

10. Attwell K, Beer A, Statens Byggeforskningsinstitut., The European Network on Urban Density and Green Structure. 1999. Ecological sustainability and urban greenspace: proceedings of the Ringkøbing seminar August 1998. Hørsholm: Danish Building Research Institute. 112 sider $\mathrm{pp}$.

11. Dahl JP, Avery J. 1984. Local density approximations in quantum chemistry and solid state physics. New York ; London: Plenum Press. xiii, 851 sider pp.

12. Schmidt T, Elers T, Jensen I, Bloch C, Hamshore R, Hirsbro A. 1996. Europe endless : the highest state of trance. Outloud : X-Ray. 2 cd'er. pp.

13. Hinchliffe A, Aicken FM, Royal Society of Chemistry. 2000. Chemical modelling : applications and theory : a review of the literature published up to June 1999. Cambridge: Royal Society of Chemistry. xvii, 505 s. pp.

14. Lewis DA, Charnock P, Royal Society of Chemistry. 1980. Index of reviews in organic chemistry. London: Royal Society of Chemistry. 166 s. pp.

15. Lewis DA, Royal Society of Chemistry. 1981. Index of reviews in organic chemistry. London: Royal Society of Chemistry. 181 s. pp.

16. Fédération nationale des déportés et internés résistants et patriotes (France)., Ecritures et pratiques dans les prisons et les camps de concentration nazis :, Musée des beaux-arts (Reims France)., Université de Reims Champagne-Ardenne. 1996. Créer pour survivre : actes $d u$ colloque international "Ecritures et pratiques dans les prisons et les camps de concentration nazis" organisé à Reims les 20, 21 et 22 septembre 1995, par l'Université de Reims Champagne Ardenne et la Fédération Nationale des Déportés et Internés Résistants et Patriotes (FNDIRP). Paris: Fédération Nationale des Déportés et Internés Résistants et Patriotes. 263 s. pp.

17. Linda R, Ef. kommission. studies. evolution of concentration and competition series a44. 1979. International sectoral comparisons including analyses on the beverages industries in germany and europe, 1. Luxembourg,. 270 s. pp.

18. Marfels C, Ef. kommission. studies. evolution of concentration and competition series b44. 1979. International sectoral comparisons including analyses on the beverages industries in germany and europe. 2. Luxembourg,. 137 s. pp.

19. Symposium on Media Concentration :, USA. Federal Trade Commission. Bureau of Competition. 1979. Proceedings of the Symposium on Media Concentration : december 14 and 15, 1978. Washington, D.C.: Bureau of Competition, Federal Trade Commission. bd. pp.

20. Angus S, Armstrong B, Reuck KMd, International union of pure and applied chemistry physical chemistry division Commission on thermodynamics Thermodynamic tables project. 1978. Methane: IUPAC chemical data series 16. Oxford 1978. 251 s. pp.

21. Angus S, Armstrong B, Reuck KMd, International union of pure and applied chemistry. Physical chemistry division Commission on thermodynamics and thermochemistry Thermodynamic tables project., IUPAC. 1976. Carbon dioxide. Oxford 1976,,. 385 s. pp. 
22. Angus S, Reuck KMd, Armstrong B, International union of pure and applied chemistry. Physical chemistry division Commission on thermodynamics Thermodynamic tables project., IUPAC. 1979. Nitrogen. Oxford 1979,.. 244 s. pp.

23. Angus $\mathrm{S}$, Reuck KMd, MacCarty RD, International union of pure and applied chemistry Physical chemistry division Commission on thermodynamics and thermochemistry Thermodynamic tables project. 1977. Helium 4. Oxford 1977. 265 s. pp.

24. Institution of Mechanical Engineers. Thermodynamics and Fluid Mechanics Group., IME., IMechE. 1968. Heat transfer and fluid dynamics of near critical fluids. University of Bristol, 1968. A symposium arranged by the Thermodynamics and fluid mechanics group of the Institution of mechanical engineers : Symposium on heat transfer and fluid dynamics of near critical fluids 1968. London 1968,,. 71 s. pp.

25. Center for History of Physics. 1980. Preliminary finding aid to the archives of the Lick Observatory: from the card catalog maintained by the Lick Observatory Archives Staff, University of California at Santa Cruz. New York: American Institute of Physics. viii, 56 s. pp.

26. Jørgensen PET, Muhly PS. 1987. Operator algebras and mathematical physics : proceedings of a summer conference held June 17-21, 1985, with support from the National Science Foundation and the University of Iowa. Providence, R.I.: American Mathematical Society. xii, 544 s. pp.

27. Niels Bohr Library. 1994. Guide to the archival collections in the Niels Bohr Library at the American Institute of Physics. College Park, Md.: American Institute of Physics. 574 s. pp.

28. Danmark. Miljøstyrelsen. 1998. Effects of organic chemicals in sludge applied to soil : degradation and toxicity to organisms living in soil. Kbh.Haslev: Ministry of Environment and Energyeksp. Nordisk Bog Center. 36 sider pp.

29. Institution of Water and Environmental Management. 1993. Glossary. London: Institution of Water and Environmental Management. 119 s. pp.

30. National Research Council (USA). Committee on Risk Assessment of Exposure to Radon in Drinking Water. 1999. Risk assessment of radon in drinking water. Washington: National Academy Press. xiii, 279 s. pp.

31. Ejling Larsen S, Friberg N, Rebsdorf A, Danmark. Danmarks Miljøundersøgelser. 1999. Proceedings of the 12th Task Force Meeting in Silkeborg, Denmark, October 23-25, 1996 : convention on long-range transboundary air pollution : international cooperative programme on assessment and monitoring of acidification of rivers and lakes. Roskilde: Miljø- og energiministeriet, Danmarks miljøundersøgelser. 49 s. pp.

32. EPICA Task Force., EPICA Task Force. 1982. Grenada : the peaceful revolution. Washington: EPICA. 132 s. pp.

33. Goldish MD, Popkin RH, Kottman KA, Force JE. 2001. Millenarianism and Messianism in early modern European culture. Dordrecht: Kluwer Academic. 4 bd. pp.

34. Ferrer AMG, del Val NJ, Ianniciello C, Critical Cartography of Art and Visuality in the Global Age :. 2014. Critical cartography of art and visuality in the global age. Newcastle upon Tyne: Cambridge Scholars Publishing. 352 s. pp.

35. Crowe A, Rudge MRH, International Symposium on Correlation and polarisation in electronic and atomic collisions :. 1988. Proceedings of the international symposium on correlation and polarisation in electronic and atomic collisions, 30-31 July, 1987. Singapore: World Scientific. 352 s. pp.

36. Kertes AS, Salomon M, International Union of Pure and Applied Chemistry. Analytical Chemistry Division Commission on Equilibrium Data Subcommittee on Solubility Data., IUPAC. 1979. Solubility data series. - 3: Silver azide, cyanide, cyanamides, cyanate, selenocyanate and thiocyanate: Solubilities of solids. Oxford: Pergamon. 19+247 s. pp.

37. Kertes AS, Clever HL, International Union of Pure and Applied Chemistry. Analytical Chemistry Division Commission on Solubility Data., IUPAC. 1980. Solubility data series. 4: Argon. Oxford: Pergamon. 18+331 s. pp.

38. Coulomb J. 1972. Sea floor spreading and continental drift. Dordrecht: D. Reidel. 184 s. pp.

39. Coulomb Md, du Vauroux CP. 1919. Fiancée de guerre. Paris Barcelone,. 207 S. pp. 
40. Delobeau F. 1967. L'environnement de la terre. Paris: Presses Universitaires de France. $8+$ 163 s. pp.

41. Blixt Å. 1987. Microvascular distribution of leukocytes : microscopic studies on leukocyte network and venular radial distribution. Akad avh. University of Göteborg,, Göteborg. $92 \mathrm{~s}$. pp.

42. H.C. Ørsted Institutet. Fysisk Laboratorium. 1986. Report. Copenhagen: H.C. Ørsted Institute

43. Linderstrøm-Lang CU. 1970. Vortex tubes with weak radial flow. Atomenergikommissionen i kommission hos Gjellerups Boghandel. bind. pp.

44. McGregor DC. 1961. Spores with proximal radial pattern from the Devonian of Canada. Tr. i Ottawa: Thorn Press. 12 s. 1 tvl. pp.

45. Møller Rasmussen S, Bruun T. 1989. Endemi. Kbh.: Arme \& Ben. 200 sider pp.

46. Munk SM. 1995. Centralized monitoring of $10 \mathrm{kV}$ cable based radial distribution networks. $\mathrm{Ph} \mathrm{d}$-afhandling. Electronics Institute, Technical University of Denmark,, Lyngby. iv, VI, 173 sider pp.

47. Norberg B. 1971. Contractile processes in human lymphocytes and monocytes from peripheral blood: the oxalate-induced radial segmentation of the nuclei and the ATP-induced migration of glycerinated cell models. Doktordisputats, Lund Universitet. Munksg@ård,. 29 sider pp.

48. Norberg B. 1971. Contractile processes in human lymphocytes and monocytes from peripheral blood: The oxalate-induced radial segmentation of the nucler and the ATPinduced migration of glycerinated cell models. Cph. (tr. Lund): Munksgaard. 29 s. (multigr.). pp.

49. Saikku LA. 1947. Tendon transplantation for radial paralysis : Factors influencing the results of tendon transplantation. Helsingfors,. $121 \mathrm{~S}$. pp.

50. Smith B, Scott AS, Ari, Oban G, Beresford S, et al. New Age Steppers. Statik. 1 grammofonplade pp.

51. Baus M, Rull LF, Ryckaert J-P, NATO Advanced Study Institute on Observation Prediction and Simulation of Phase Transitions in Complex Fluids :. 1995. Observation, prediction and simulation of phase transitions in complex fluids. Dordrecht: Kluwer Academic Publishers. xvii, 664 s. pp.

52. Jo.C.Fine., Phase, Yo A, Josefine. 1989. Jo.C.Fine. Pladecompagniet. 1 grammofonplade pp.

53. Jo.C.Fine., Phase, Yo A, Josefine. 1989. Respekt. Pladecompagniet. 1 grammofonplade pp.

54. NATO Advanced Study Institute on Phase Transitions in Soft Condensed Matter : 1989 : Geilo)., Riste T, Sherrington DC. 1989. Phase transitions in soft condensed matter : proceedings of a NATO Advanced Study Institute on Phase Transitions in Soft Condensed MAtter, held April 4-14, 1989, in Geilo, Norway. New York: Plenum Press : publ. in cooperation with NATO Scientific Affairs Division. ix, 391 s. pp.

55. Starks CM, Liotta C. 1978. Phase transfer catalysis : principles and techniques. New York: Academic Press. ix, 365 s. pp.

56. Buch Salomonsen K. 2000. Potentiale og barrierer for biogasproduktion i Danmark ved omfattende økologisk jordbrug med fokus på dyrkningsjordens kulstofforhold. $\mathrm{Ph} \mathrm{d}-$ afhandling. Institut for Bygninger og Energi, Danmarks Tekniske Universitet,, Lyngby. 83 s. pp.

57. Danmark. DANCED. 2000. Thailand-Danish country programme for environmental assistance 1998-2001. Copenhagen: DANCED : available from: ... Miljøbutikken. 49 sider. pp.

58. International Energy Agency. 1989. Electricity end-use efficiency. Paris: OECD. 200 s. pp.

59. OECD. International Energy Agency. 2000. Energy policies of IEA countries: Sweden 2000 review. Paris: Organisation for Economic Co-operation and Development. 142 s. pp.

60. OECD. Nuclear Energy Agency., Sverige. Statens strålskyddsinstitut., Swedish National Institute of Radiation Protection., National Institute of Radiation Protection. 1990. Emergency preparedness for nuclear-powered satellites : Stockholm, Sweden, 24-26 april 1989. Paris: OECD. 103 s. pp.

61. Beard TR, Lozada GA. 1999. Economics, entropy and the environment : the extraordinary economics of Nicholas Georgescu-Roegen. Cheltenham: Edward Elgar. viii, 155 s. pp. 
62. Brooks DR, Wiley EO. 1986. Evolution as entropy : toward a unified theory of biology. Chicago: University of Chicago Press. xiv, 335 s. pp.

63. Fast JD. 1970. Entropy : the significance of the concept of entropy and its applications in science and technology. London: Macmillan. xii, 339 s. pp.

64. Leff HS, Rex AF. 1990. Maxwell's demon : entropy, information, computing. Bristol: Adam Hilger. xii, 349 s. pp.

65. Martin NFG, England JW. 1984. Mathematical theory of entropy. Reading, Mass.: AddisonWesley. xxi, 257 s. pp.

66. Christensen LJ, Kjær J, Haldor Topsøe. 1982. Enthalpy tables : Ideal gases. Ravnholm,.. 270 s. pp.

67. Loscil., Morgan S. 2001. Triplepoint. Chicago, Ill.: Kranky. 1 cd. pp.

68. OECD. Nuclear energy agency. 1997. Modelling in aquatic chemistry. Paris: Nuclear Energy Agency. liii, 724 s. pp.

69. Poling BE, Praunitz JM, O'Connell JP. 2000. The Properties of Gases and Liquids. McGrawHill. sev. pag. pp.

70. $\quad$ Shao W. Saturated vapor pressure and enthalpy for R134a-oil and R152a-oil mixtures. S. 22$5 \mathrm{pp}$.

71. Barbour RS, Kitzinger J. 1999. Developing focus group research : politics, theory and practice. London: SAGE. xiii, 225 s. pp.

72. Barton H, Gilchrist A. 2000. Sustainable communities : the potential for eco-neighbourhoods. London: Earthscan. xix, 305 s. pp.

73. European Commission. 1999. Blue book on geothermal resources: this report has been prepared for the European Commission by: CESEN, BRGM, ETSU, GTN, ORKUSTOFNUN. Luxembourg: Office for Official Publications of the European Communities. xxviii, 527 sider pp.

74. Niklasson G. 1995. Synthesis of saccharide derivatives and potential inhibitors of HIV. Disputats, Linköping universitet. Department of Physics and Measerement Technology, Chemistry, Linköping University,, Linköping. 125 s. pp.

75. OECD., International Energy Agency. 2001. Oil supply security : the emergency response potential of IEA countries in 2000. Paris: International Energy Agency : Organisation for Economic Co-operation and Development. 370 s. pp.

76. Okazaki T, Okuno-Fujiwara M. 1999. The Japanese economic system and its historical origins. Oxford: Oxford University Press. x, 294 s. pp.

77. Riverson JDN, Carapetis S, World Bank. 1991. Intermediate means of transport in subSaharan Africa : its potential for improving rural travel and transport. Washington, D.C.: World Bank. 27 s. pp.

78. Tengström E. 1999. Towards environmental sustainability? : a comparative study of Danish, Dutch and Swedish transport policies in a European context. Aldershot: Ashgate. xxviii, 241 s. pp.

79. Union of International Associations. Encyclopedia of world problems and human potential. 1 bd. (flere pag.). München pp.

80. Wareing PF, Cooper JP. 1971. Potential crop production : [papers given at a symposium on "Poential Crop Production in Britain", held in Aberystwyth in July 1969]. London: Heinemann Educational Books. xi, 387 s. pp.

81. Andersson B. 1982. Damping due to friction in the gear mesh of vibrating helical gears. Göteborg: Chalmers University of Technology, Division of Machine Elements. 95 s. pp.

82. Bay N. 1986. Friction and adhesion in metal forming and cold welding. Disp. DTH,, Lyngby. 629 s. pp.

83. Bowden FP, Tabor D. 1974. Friction : an introduction to tribology. London: Heinemann. 178 s. pp.

84. Chadwick O. 1984. Hensley Henson : a study in the friction between Church and State. Oxford: Clarendon Press. xi, 337 s. pp.

85. Hamada K, Matsushita M, Komura C, Seikei University. Center for Asian and Pacific Studies., Institute of Southeast Asian Studies. 2000. Dreams and dilemmas : economic friction and dispute resolution in the Asia-Pacific. Singapore: ISEAS. xxi, 494 s. pp. 
86. Jendeby L. 1986. Friction piled foundations in soft clay : a study of load transfer and settlements. Akad avh. Department of Geotechnical Engineering,, Göteborg. (Fl.pag.) pp.

87. Karlsson RI. 1980. Studies of skin friction in turbulent boundary layers on smooth and rough walls. Akad avh. Chalmers Tekniska Högskola, Department of applied thermo and fluid dynamics, Göteborg. 17 bl. pp.

88. Pedersen FB. 1980. A monograph on turbulent entrainment and friction in two-layer stratified flow. Disputats, Danmarks Tekniske Højskole. Technical University of Denmark,, Lyngby. 397 s. pp.

89. Sellgren E. 1981. Friction piles in non-cohesive soils : evaluation from pressuremeter tests. Göteborg: Department of Geotechnical Engineering, Chalmers University of Technology. 215 s. pp.

90. Slim TB, Rosemont F. 1992. Juice is stranger than friction : selected writings of T-Bone Slim. Chicago,: Charles H. Kerr. 159 s. pp.

91. Borges JL, Poulsen P. 2001. Digte 1923-85. Kbh.: Gyldendal. 256 sider. pp.

92. Compaine BM. 2001. The digital divide : facing a crisis or creating a myth? Cambridge, Mass.: MIT. xvi, 357 s. pp.

93. Europa-Kommissionen. 1996. Foellesskabets socialpolitik : programmer, net og observationsorganer. Luxembourg: Kontoret for De Europæiske Fællesskabers Officielle Publikationer. 113 s. pp.

94. Höring K. 1985. Interne Netzwerke für die Bürokommunikation : Technik und Anwendungen digitaler Nebenstellenanlagen und von Local Area Networks (LAN). Heidelberg: Decker's Verlag. xiv, 431 s. pp.

95. Jensen S. 2002. Introduktion til datakommunikation. Kbh.: Ingeniøren-bøger. 305 sider pp.

96. Cole P, Hermon G, Huang CTJ. 2001. Long-distance reflexives. San Diego, Calif.: Academic. xlvii, 378 s. pp.

97. Harry K. 1985. Distance education in Western Europe : a selective annotated bibliography of current literature. Luxembourg: Office for Official Publications of the European Communities. 174 s. pp.

98. Hogarth T, Daniel WW, Policy Studies Institute. 1988. Britain's new industrial gypsies : long distance weekly commuters. London: Policy Studies Institute. 93 s. pp.

99. Hollings D, Inwood H, Sheldon R, Economist Intelligence Unit. 1991. European railways : prospects for long distance passenger services in the 1990s. London: EIU, The Economist Intelligence Unit. $155 \mathrm{~s}$. pp.

100. Holmberg B. 1977. Distance education : a survey and bibliography. London: Kogan Page. 167 s. pp.

101. Leth T, Danmark. Levnedsmiddelstyrelsen. Centrallaboratoriet. Afdeling A., Danmark. Levnedsmiddelstyrelsen. 1986. Kartoflers indhold af noeringsstoffer og nitrat : planteafstand, optagningstidspunkt og gødskning $=$ The nutrient and nitrate content in potatoes. SøborgKbh.: Centrallaboratoriets afdeling Aeksp. DBK. 30 sider pp.102. Maddux CD. 1992. Distance education : a selected bibliography. Englewood Cliffs, N.J.: Educational Technology Publications. 71 bl. pp.

103. Marantz A, Miyashita Y, O'Neil W, Mind Articulation Project Symposium. 2000. Image, language, brain : papers from the First Mind Articulation Project Symposium. Cambridge, Mass.: MIT Press. x, 272 s. pp.

104. Mead M, Métraux R. 2000. The study of culture at a distance. New York: Berghahn Books. xxxiv, 541 s. pp.

105. Odde Sørensen D. 1992. Massekultur mellem distance og beherskelse : om massen, det sociale og identitet i det moderne. Konferensspeciale. Københavns Universitet,, Kbh. $112 \mathrm{~s}$. pp.

106. 1976. The charge of the Federal Prosecution against Kurt Groenewold as defence counsel of Red Army Fraction (RAF) prisoners. Hamburg, 57 s. pp.

107. Abercrombie N, Warde A, Deem R. 2000. Contemporary British society. Cambridge: Polity Press. xx, 602 s. pp.

108. Alderson P. 2000. Young children's rights : exploring beliefs, principles and practice. Philadelphia, Pa.: J. Kingsley. 160 s. pp. 
109. Arber S, Attias-Donfut C. 2001. The myth of generational conflict : the family and state in ageing societies. London: Routledge. xii, $232 \mathrm{s.pp}$.

110. Arrabal F. 1969. Théâtre. Paris: Christian Bourgois. 12 bd., tav. pp.

111. Bai W, Ingeniørhøjskolen Horsens Teknikum. Laboratoriet for Geoteknik. 1991. Resistivity prospecting in water resource investigations. Horsens: Geotechnical Laboratory, State Recognized Engineering College of Horsens. IV, 46 sider pp.

112. Baker O, Mounteney J, Danmark. European Monitoring Centre for Drugs and Drug Addiction. Workshop :. 1999. Evaluating the treatment of drug abuse in the European Union : papers arising from an EMCDDA workshop held in Athens, Greece, on 17-18 March 1997. Luxembourg: Office for Official Publications of the European Communities. 135 s. pp.

113. Berkson W. 1974. Fields of force : the development of a world view from Faraday to Einstein. London: Routledge and Kegan. xiii, 370 s. pp.

114. Blundell D, Freeman R, Mueller S. 1992. A continent revealed: the European geotraverse. Cambridge: Cambridge University Press. xi, 275 s., 1 hæfte (73 s.), 1 cd-rom, 27 kort, alt i 1 kassette. pp.

115. Cantor G. 1993. Michael Faraday : Sandemanian and scientist : a study of science and religion in the nineteenth century. Basingstoke: Macmillan P. xi, 359 s. pp.

116. Ciampa D, Watkins M. 1999. Right from the start : taking charge in a new leadership role. Boston, Mass.: Harvard Business School Press. xiv, 316 s. pp.

117. Esam P, Oppenheim C, Child Poverty Action Group. 1989. A charge on the community : the poll tax, benefits and the poor. London: Child Poverty Action Group. vii,152 s. pp.

118. Gerischer H, Katz JJ, Dahlem Workshop on Light-Induced Charge Separation at Interfaces in Biological and Chemical System :. 1979. Light-induced charge separation in biology and chemistry : report of the Dahlem Workshop on Light-Induced Change Separation at Interfaces in Biological and Chemical Systems Berlin 1978, October 16-20. Weinheim: Chemie. 562 s. pp.

119. Gibert E. 1987. Analyse comparée de l'évolution des services dans les grandes nations occidentales : rapport au ministre délégué chargé du commerce de l'artisanat et des services. Paris: Documentation française. 163 s. pp.

120. International Symposium on Charge and Field Effects in Biosystems (4 : 1994 : Virginia Commonwealth University)., Allen MJ, Cleary SF, Sowers AE. 1994. Proceedings of the 1994 International Symposium on Charge and Field Effects in Biosystems--4 : Virginia Commonwealth University,Richmond, Virginia, 20-24 June, 1994. New Jersey: World Scientific. xiv, 527 s. pp.

121. Lawton TC, Rosenau JN, Verdun AC. 2000. Strange power : shaping the parameters of international relations and international political economy. Aldershot: Ashgate. xxii, $453 \mathrm{~s}$. pp.

122. Paul R, Elder L. 2001. Critical thinking : tools for taking charge of your learning and your life. Upper Saddle River, N.J.: Prentice Hall. xx, 428 s. pp.

123. Cantor GN, Gooding D, James FAJL. 1996. Michael Faraday. Atlantic Highlands, NJ: Humanities Press. 111 s. pp.

124. Faraday M, James FAJL. 1991. The correspondence of Michael Faraday. Stevenage: Institution of Electrical Engineers. 4 bd. pp.

125. Faraday Society. Transactions of the Faraday Society. - London.

126. Gooding D, James FAJL. 1985. Faraday rediscovered : essays on the life and work of Michael Faraday, 1791-1867. Basingstoke: Macmillan. xiv,258 s. pp.

127. Gribbin J, Gribbin M. 1997. Faraday (1791-1867) in 90 minutes. London: Constable. $80 \mathrm{~s}$. pp.

128. Thomas JM. 1997. Michael Faraday and the Royal Institution : (the genius of man and place). Bristol: Institute of Physics Publishing. xii, 234 s. pp.

129. Gerasimov IP, International Geographical Congress. 1976. International geography ' 76 : xxiii International Geographical Congress $=$ Geographie internationale '76 $=$ Me@02C7zdunarodnajageografija '76. Oxford: Pergamon Press. 12 bd. pp.

130. Hazewinkel M. 1988. Encyclopaedia of mathematics : an updated and annotated translation of the Soviet "Mathematical encyclopaedia". Dordrecht: Reidel : Kluwer. 13 bd. pp. 
131. Kärger J, Heitjans P, Haberlandt R. 1998. Diffusion in condensed matter. Braunschweig: Vieweg. xii, 391 s. pp.

132. Masser I, Campbell H, Craglia M. 1996. GIS diffusion : the adoption and use of geographical information systems in local government in Europe. London: Taylor \& Francis. xx, 238 s. pp.

133. Møller PND, Handelshøjskolen i København. Det økonomiske fakultet. 1999. Exchange rates in target zones : the case of diffusion models. København: Department of Operations Management Science and Statistics Samfundslitteratur. 124 s. pp.

134. Northcott J, Walling A, Policy Studies Institute. 1988. The impact of microelectronics : diffusion, benefits and problems in British industry. London: Policy Studies Institute. $304 \mathrm{~s}$. pp.

135. OECD. 1996. Technology and industrial performance : technology diffusion, productivity, employment and skills, international competitiveness. Paris: Organisation for Economic CoOperation and Development. 197 s. pp.

136. Stoneman P. 2002. The Economics of Technological Diffusion. Malden, MA: Blackwell Publishers. ix, 317 s. pp.

137. Tilton JE. 1971. International diffusion of technology : the case of semiconductors. Washington: The Brookings Institution. 183 s. pp.

138. Underdal A, Hanf K. 2000. International environmental agreements and domestic politics: the case of acid rain. Aldershot: Ashgate Publishing Limited. xiv, 384 s. pp.

139. Dunn JA. 1998. Driving forces : the automobile, its enemies, and the politics of mobility. Washington: Brookings Institution Press. x, 230 s. pp.

140. Even Rasmussen L, Amternes og Kommunernes Forskningsinstitut. 2001. Mobility out of socially deprived residential areas. Kbh.: AKF. 71, 11 sider pp.

141. Hibbs J. 1993. On the move - : a market for mobility on the roads. London: Institute of Economic Affairs. 95 s. pp.

142. Kahlenberg RD. 2000. A notion at risk: preserving public education as an engine for social mobility. New York: Century Foundation. vii, 356 s. pp.

143. Savage M. 2000. Class analysis and social transformation. Buckingham: Open University Press. xvi, 185 s. pp.

144. Tassinopoulos A, Werner H, Kristensen S, Europæiske Center for Udvikling af Erhvervsuddannelse. 1998. Mobility and migration of labour in the European Union and their specific implications for young people. ThessalonikiLuxembourg: CEDEFOP ;Office for Official Publications of the European Communities. 126 sider. pp.

145. Hittorf JW. 1903. Über die Wanderungen der Ionen während der Elektrolyse : abhandlungen...(1853-1859) : 1. Theil mit 1 Tafel. Leipzig,. ?. pp.

146. Hittorf W. 1891. Über die Wanderungen der Ionen während der Elektrolyse Ostwald's Klassiker No. 21 (Erste Hälfte) Ostwald's Klassiker No. 22 (Zweite aälfte). Lpz.,. pp. $87+$ 142. pp.

147. Hittorf W. 1904. Über die Wanderungen der Ionen während der Elektrolyse : abhandlungen...(1853-1859) : 2. Teil mit 1 Tafel. Leipzig,. ?. pp.

148. Hittorf W. 1986. Ueber die Wanderungen der Ionen während der Elektrolyse : Abhandlungen (1853-1859). Leipzig: Geest \& Portig. 115, 42 s. pp.

149. Hittorf W, Ostwald W. 1891. Ostwald's Klassiker der exakten Wissenschaften Nr.21: Über die Wanderungen der Ionen während der Elektrolyse. (1853-59) 1 theil. Engelmann: Leipzig. 87 1. pp.

150. Hittorf W, Ostwald W. 1891. Ostwald's Klassiker der exakten Wissenschaften Nr.23: Über die Wanderungen der Ionen wärend der Elektrolyse. (1853-59) 2.Theil. Engelmann: Leipzig. 142 1. pp.

151. Ostwald's Klassiker der exakten Wissenschaften (21 23., Hittorf W. 1891. Ueber die Wanderungen der Ionen während der Elektrolyse : Abhandlungen. Leipzig: Engelmann. 2 bd. pp.

152. Plücker J, Hittorf JW. 1904. On the spectra of ignited gases and vapours with especial regard to the different spectra of the same elementary gaseous substance : neudruck aus den Philosophical Transactions of the Royal Society of London for 1865 Vol. 155, veranstaltet zum 80. Geburtstage Wilhelm Hittorfs. Leipzig,. 39 s. 1 Portr. 3 Tvl. pp. 
153. Dahlin T. 1993. On the automation of $2 D$ resistivity surveying for enginnering and environmental applications. Akad avh. Department of Engineering Geology, Lund Institute of Technology, Lund University,, Lund. 187 s. pp.

154. Habberjam GM. 1979. Apparent resistivity observations and the use of square array techniques. Berlin: Gebrüder Borntraeger. 152 s. pp.

155. Koefoed O. 1979. Geosounding principles 1 : Resistivity sounding measurements. Amsterdam: Elsevier. xiv, 276 s. pp.

156. Koefoed O, Mallick K, Patra HP. 1979. Geosounding principles. Amsterdam: Elsevier Scientific. 2 bd. pp.

157. Pulawski B, Klitten K. 1979. Combined use of resistivity and seismic refraction methods in groundwater prospecting in crystalline areas : study project, Kenya 1977. Kbh.: DANIDA. 56 blade, 64 tavler pp.

158. Wang S, Lindelof PE. 1987. Weak localization experiments on magnesium films : effects of substrate, ion-implantation, microwaves, temperature and resistivity/thickness on the phase and spin-orbit relaxation. S.1.: s.n. 58 s., tav. pp.

159. Bjerreg@ård JO, Heje L, Bidstrup O, Dansk Vestindisk Selskab. 1991. Fra slavesang til Soca : historien om og musikken fra de tidligere Dansk-Vestindiske Øer. Årslev: Dansk Vestindisk Selskab. 63 sider pp.

160. Cesareo G, Rodi P. 1996. Il mercato dei sogni : introduzione alla comunicazioni di massa. Milano: Bruno Mondadori. 206 s. pp.

161. dk-Teknik. 1990. Industriell gasanvändning i Norden : en branschanalys. Hørsholm: Nordisk Gasteknisk Center. 3 bd pp.

162. Eco U. 1986. Il superuomo di massa. Milano: Bompiani. 184 s. pp.

163. Eskelinen V, Nordisk Råd., Nordisk Ministerråd. 1985. Energibesparing inom massa- och papperindustrin. Kbh.: Nordisk Ministerråd : eksp. Energistyrelsen. 34 sider pp.

164. Crystal D. 1981. Directions in applied linguistics. London: Academic Press. 179 s. pp.

165. Crystal D. 1991. Rediscover grammar with David Crystal. Harlow: Longman. 223 s. pp.

166. Crystal D. 1998. The Cambridge biographical encyclopedia. Cambridge: Cambridge University Press. xi, 1179 s. pp.

167. Crystal D. 1998. Language play. London: Penguin Books. 248 s. pp.

168. Crystal D. 2000. Language death. Cambridge: Cambridge University Press. x, 198 s. pp.

169. Heller J, Vogel S. 1986. No laughing matter. London: Jonathan Cape. 335 s. pp.

170. High-Level Group "The European High-Speed Train Network". 1995. L'Europe à grande vitesse = High-speed Europe = Hochgeschwindigkeit Europa. Luxembourg: Office for Official Publications of the European Communities. 168 s. pp.

171. Kowalik JS, NATO Advanced Research Workshop on High-Speed Computation :, North American Treaty Organization. Scientific Affairs Division. 1984. High-speed computation. Berlin: Springer. 441 s. pp.

172. Speed K. 1982. Sea change : the battle for the Falklands and the future of Britain's navy. Bath: Ashgrove Press. 194 s., tav. pp.

173. Speed R. 1979. Strategic deterrence in the 1980s. Stanford, Calif.: Hoover Institution Press. 174 s. pp.

174. Grissmer S, International Potassium Channel Conference :. 1997. International Potassium Channel Conference, 16-19 July 1997, Ulm, Germany : abstracts. Berlin: Springer. S. R74R112. pp.

175. Incident CtAtD, Administration of Potassium Iodide in the Event of a N. 2004. Distribution and Administration of Potassium Iodide in the Event of a Nuclear Incident. Washington: National Academies Press

176. Kilmer VJ, Younts SE, Brady NC, (The) role of potassium in agriculture :, symposium. 1968. The role of potassium in agriculture: Proceedings of a symposium sponsored and financed by the Tennessee Valley Authority and the American Potash Institute... and held at the National Fertilizer Development Center, TVA, Alabama, June 18-19,1968. Madison, Wisconsin: American Society of Agronomy, Crop Science Society of America, and Soil Science Society of America. 509 s. pp. 
177. National Research Council (U.S.). Committee to Assess the Distribution and Administration of Potassium Iodide in the Event of a Nuclear Incident., National Research Council (U.S.). Board on Radiation Effects Research. 2004. Distribution and administration of potassium iodide in the event of a nuclear incident. Washington, DC: National Academies Press. xiii, 248 s. pp.

178. Potassium in soils crops and fertilizers :, symposium., Indian Society of Soil Science. 1976. Potassium in soils, crops and fertilizers : papers presented at a symposium on...1975. New Delhi: The Society. 345 s. pp.

179. Storbritannien. Potassium Institute. Colloquium proceedings. Henley-on-Thames, Oxf.: Potassium Institute.

180. Eaton S, Fatty Acid Oxidation and Ketogenesis Conference. 1999. Current views of fatty acid oxidation and ketogenesis from organelles to point mutations. New York: Kluwer Academic/Plenum Publishers. xvii, 414 s. pp.

181. Inoue Y, International Symposium on Photosynthetic Water Oxidation and Photosystem II Photochemistry :. 1983. The oxygen evolving system of photosynthesis. Tokyo: Academic Press. 459 s. pp.

182. Mayo FR, International Oxidation Symposium :. 1968. Oxidation of organic compounds : proceedings of the international oxidation symposium, arranged by Stanford Research Institute in San Francisco, Calif., Aug. 28 - Sept. 1, 1967. Wash., D.C.,. 3 bd. pp.

183. Miners JO, International Symposium on Microsomes and Drug Oxidation. 1988. Microsomes and drug oxidations : Proceedings of the 7. international symposium, Adelaide, Australia, 1721 August, 1987. London: Taylor and Francis. 412 sider. pp.

184. Tanaka K, Coates PM, International Symposium on Clinical Biochemical and Molecular Aspects of Fatty Oxidation :. 1990. Fatty acid oxidation : Clinical, biochemical, and molecular aspects : Proceedings of the International Symposium on Clinical, Biochemical and Molecular Aspects of Fatty Oxidation held in Philadelphia, Pa., November 6-9,1988. New York: Alan R. Liss. $22+728$ sider. pp.

185. EMCDDA European Monitoring Centre for Drugs and Drug Addiction. 2000. Evaluation : $a$ key tool for improving drug prevention : papers from the second European conference ... Strasbourg, France, from 2 to 4 December 1999. Luxembourg: Office for Official Publications of the European Communities. 184 s. pp.

186. EMCDDA. 1999. Extended annual report on the state of the drugs problem in the European Union 1999. Luxembourg: Office for Official Publications of the European Communities. 94 s. pp.

187. Fountain J, European Monitoring Centre for Drugs and Drug Addiction., EMCDDA. 2000. Understanding and responding to drug use : the role of qualitative research. Luxembourg: Office for Official Publications of the European Communities. 352 s. pp.

188. Korf DJ. 1999. Outreach work among drug users in Europe : concepts, practice and terminology. Luxembourg: Office for Official Publications of the European Communities. 195 s. pp.

189. Crane H, Weber B. 1987. Complete poems. Newcastle upon Tyne: Bloodaxe Books. 222 sider. pp.

190. Weber B. 1964. Sherwood Anderson. Minneapolis, Minn.: University of Minnesota Press. 48 s. pp.

191. Silver H, Re@017Eábek M, Blaha J, George D, Ellington D, et al. 1966. Kazatel = The preacher / Temná naláda : mood indigo ; D. Ellington, arr. J. Hnili@010Dka ; Franti@0161ek Navrástil, altsaxofon ; Pochod jazzové policie ; J. Blaha ; Stanislav Veselýa Josef Pulec, trombón ; [det hele]: Gustav Brom se svým orchestrem. Supraphon. 1 grammofonplade pp.

192. Donida, Mogol, Fiala J, Bléharová H, Werner, et al.1966.A@017E@0161ipky rozkvetou / Happy end; Werner, Bochmann, Jan Fiala ; zp. Helena Bléharová, @0160tepán Mátl a sbor ; [begge]: Gustav Brom se svým orchestrem. Supraphon. 1 grammofonplade pp.

193. Backman R. 1989. Sodium and sulfur chemistry in combustion gases. Disputats, Åbo akademi. Åbo akademi,, Åbo. 1 bd. (flere pag.). pp. 
194. Eriksson S. 1982. Cerebrospinal fluid salinity and body fluid homeostasis : studies on putative juxtacerebroventricular sodium sensitivity in the goat. Thesis. s.n. ,, Stockh. 35 s. pp.

195. Fitzsimons JT, Physiological Society. 1979. The physiology of thirst and sodium appetite. Cambridge: Cambridge University Press. xv, 572 s. pp.

196. Hansen HS. 1993. Blood pressure, physical fitness, cardiac structure and sodium-potassium pump activity in a population of children : the impact of primary intervention with physical training : the Odense schoolchild study. Disputats, Odense Universitet. Eget forlag,, Odense. 65 sider pp.

197. Kornerup HJ. 1980. Pathophysiological and clinical aspects concerning the renin-angiotensin system and the body sodium content in renal and postrenal-transplant hypertension in humans : a survey. Disputats, Århus. Århus Universitet,, Århus. 58 s. pp.

198. Meyland I, Statens Levnedsmiddelinstitut. 1983. Magnesium-, natrium- og kaliumindholdet $i$ danske levnedsmidler $=$ The content of magnesium, sodium and potassium in Danish foods. Søborg: Statens Levnedsmiddelinstitut, Centrallaboratoriets afdeling A: næringsstoffer og tilsætningsstoffer. 70 sider pp.

199. Novak L. 1979. Sodium salt scaling in connection with evaporation of black liquors and pure model solutions. Akad avh. s.n. , Göteborg. 161 s. pp.

200. Papper S. 1982. Sodium : its biologic significance. Boca Raton, Fla.: CRC. 293 s. pp.

201. Zainul, R. (2016, December 18). Design and Modification of Copper Oxide Electrodes for Improving Conversion Coefficient Indoors Lights (PV-Cell) Photocells. https://doi.org/10.31227/osf.io/pgn84

202. Zainul, R. (2016, December 18). Design and Modification of Copper Oxide Electrodes for Improving Conversion Coefficient Indoors Lights (PV-Cell) Photocells. https://doi.org/10.31227/osf.io/pgn84

203. Zainul, R. (2016, September 24). Determination of the half-life and the quantum yield of $\mathrm{ZnO}$ semiconductor photocatalyst in humic acid. https://doi.org/10.31227/osf.io/e8a9x

204. Febriani, S. S., Yolanda, T., Arianti, V. A., \& Zainul, R. (2018, September 2). A Review Solid Stated : Principles and Methode. https://doi.org/10.31227/osf.io/7us4x

205. Liza, Y. M., Yasin, R. C., Maidani, S. S., \& Zainul, R. (2018, September 29). Sol Gel : Principle And Technique (A Review). https://doi.org/10.31227/osf.io/2cuh8

206. Zainul, R. (2016, November 19). Effect of Temperature and Particle Motion against the ability of $\mathrm{ZnO}$ Semiconductor Photocatalyst in Humic Acid. https://doi.org/10.31227/osf.io/wnygb

207. Dinata, A. A., Rosyadi, A. M., Hamid, S., \& Zainul, R. (2018, August 31). A Review Chemical Vapor Deposition : Process And Application. https://doi.org/10.31227/osf.io/yfeau

208. Putri, D. F., Ritonga, H. M., Murdiati, V., \& Zainul, R. (2018, August 31). A Review What Is Hydrothermal ?. https://doi.org/10.31227/osf.io/dm56c

209. Awalliyah, A., Ikhwan, H., Nugiasari, V., \& Zainul, R. (2018, August 31). A Review Prinsip Dasar Milling Dalam Sintesis Material. https://doi.org/10.31227/osf.io/9xsqe

210. Candani, D., Ulfah, M., Noviana, W., \& Zainul, R. (2018, September 1). A Review Pemanfaatan Teknologi Sonikasi. https://doi.org/10.31227/osf.io/uxknv

211. Fatimah, P., Jumalia, R., Novianti, E. R., \& Zainul, R. (2018, August 31). A Review Teknik Blended : Prinsip dan Dasar-Dasar. https://doi.org/10.31227/osf.io/tm2w4

212. Zainul, R., Oktavia, B., Dewata, I., \& efendi, j. (2017, February 4). Studi Dinamika Molekular dan Kinetika Reaksi pada Pembelahan Molekul Air untuk Produksi Gas Hidrogen. https://doi.org/10.31227/osf.io/876s3

213. Zainul, R., Alif, A., Aziz, H., Arief, S., \& s. (2015, October 22). Photoelectrosplitting Water Mechanism at Carbon Electrode Surface using Indoor lights. https://doi.org/10.31227/osf.io/vexq8

214. Zainul, R., Alif, A., Aziz, H., Arief, S., \& s. (2015, October 22). Photoelectrosplitting Water Mechanism at Carbon Electrode Surface using Indoor lights. https://doi.org/10.31227/osf.io/vcxq8

215. M., Yani, S. R., \& Zainul, R. (2017, September 4). Aktivasi Tanah Napa dan Pengaruhnya Terhadap Adsorpsi Ion Timbal (II)/ Pb2+. https://doi.org/10.31227/osf.io/ps523 
216. P, O. M., A, L. G., S, A. Y. M., \& Zainul, R. (2018, September 1). A Review Grinding : Teknik dan Prinsip Dasar pada Pengolahan Material. https://doi.org/10.31227/osf.io/trv4q

217. H., Sanjaya, H., \& Zainul, R. (2016, August 30). Synthesis and Electrical Properties of ZnOITO and Al-ITO thin Film by Spin Coating Technique Through Sol Gel Process. https://doi.org/10.31227/osf.io/unrt4

218. M., Sanjaya, H., \& Zainul, R. (2015, December 30). Characterization of napa soil and adsorption of $\mathrm{Pb}$ (II) from aqueous solutions using on column method. https://doi.org/10.31227/osf.io/t8fh9

219. chaidir, z., Fadjria, N., A., \& Zainul, R. (2016, December 5). Isolation And Molecular Identification Of Freshwater Microalgae In Maninjau Lake West Sumatera. https://doi.org/10.31227/osf.io/nbcuf

220. chaidir, z., Zainul, R., Nurakhbari, D., \& Salim, M. (2016, September 24). Optimization of Spirulina Platensis Culture for Antioxidant Production. https://doi.org/10.17605/OSF.IO/FD6E4

221. zainul R, Oktavia B, Dewata I, Efendi J. Thermal and Surface Evaluation on The Process of Forming a $\mathrm{Cu} 2 \mathrm{O} / \mathrm{CuO}$ Semiconductor Photocatalyst on a Thin Copper Plate. Proc. IOP Conference Series: Materials Science and Engineering, 2018, 335:012039: IOP Publishing

222. Zainul R, Alif A, Aziz H, Arief S, Dradjad S, Munaf E. 2015. Design of photovoltaic cell with copper oxide electrode by using indoor lights. Research Journal Of Pharmaceutical Biological And Chemical Sciences 6:353-61

223. Mawardi M, Deyundha D, Zainul R. Characterization of PCC Cement by Addition of Napa Soil from Subdistrict Sarilamak 50 Kota District as Alternative Additional Material for Semen Padang. Proc. IOP Conference Series: Materials Science and Engineering, 2018, 335:012034: IOP Publishing

224. Anhar A, Sumarmin R, Zainul R. 2016. Measurement of Glycemic Index of West Sumatera Local Rice Genotypes for Healthy Food Selection. https://doi.org/10.31227/osf.io/tgy8h

225. Zainul R, Dewata I. 2015. Determination of pH-BOD-COD and degradation in batang arau watersheds at Padang city. 10.31227/osf.io/efdzj

226. Zainul R, Alif A, Aziz H, Arief S. 2015. Disain Geometri Reaktor Fotosel Cahaya Ruang. Jurnal Riset Kimia 8:131 https://doi.org/10.25077/jrk.v8i2.230

227. Zainul R, Alif A, Aziz H, Arief S, Darajat S. 2015. Modifikasi dan Karakteristik IV Sel Fotovoltaik Cu2o/Cu-Gel Na2so4 Melalui Iluminasi Lampu Neon. EKSAKTA 2:50

228. Yasthopi A. 2015. Photoelectrosplitting water for hydrogen production using illumination of indoor lights. Journal of Chemical and Pharmaceutical Research 7:246-56

229. Zainul R. 2015. Disain dan Modifikasi Kolektor dan Reflektor Cahaya pada Panel Sel Surya $\mathrm{Al} / \mathrm{Cu} 2 \mathrm{O}-\mathrm{Gel} \mathrm{Na} 2 \mathrm{SO} 4$. http://repository.unp.ac.id/id/eprint/610

230. Mawardi Anwar E, Kosela S, Wibowo W, Zainul R. 2015. Study of Pb (II) biosorption from aqueous solution using immobilized Spirogyra subsalsa biomass. Journal of Chemical and Pharmaceutical Research 7:715-22

231. Desy Kurniawati I, Harmiwati SS, Chaidir Z, Munaf E. Rahmiana Zein, Hermansyah Aziz, Rahadian Zainul. 2015. Biosorption of $\mathrm{Pb}$ (II) from Aqueous Solutions Using Column Method by Lengkeng (Euphoria logan lour) Seed and Shell. Journal of Chemical and Pharmaceutical Research 7:872-7

232. Zainul R, Nurakhbari D, Salim M. Optimization of Spirulina Platensis Culture for Antioxidant Production.

233. Horiza, H., Azhar, M. and Efendi, J. (2017) "Ekstraksi Dan Karakterisasi Inulin Dari Umbi Dahlia (Dahlia Sp.L) Segar Dan Disimpan”, Eksakta: Berkala Ilmiah Bidang MIPA, 18(01), pp. 31-39. doi: https://doi.org/10.24036/eksakta/vol18-iss01/14.

234. Iryani, I., Iswendi, I. and Katrina, I. T. (2017) "Uji Aktivitas Anti Diabetes Mellitus Senyawa Metabolit Sekunder Fraksi Air Dari Beras Ketan Hitam ( Oryza Satival. Var Glutinosa) Pada Mencit Putih", Eksakta: Berkala Ilmiah Bidang MIPA, 18(01), pp. 54-60. doi: https://doi.org/10.24036/eksakta/vol18-iss01/17.

235. Suryelita, S., Etika, S. B. and Kurnia, N. S. (2017) "Isolasi Dan Karakterisasi Senyawa Steroid Dari Daun Cemara Natal (Cupressus funebris Endl.)", Eksakta: Berkala Ilmiah Bidang MIPA, 18(01), pp. 86-94. doi: https://doi.org/10.24036/eksakta/vol18-iss01/23. 
236. Iskandar, I., Horiza, H. and Fauzi, N. (2017) "Efektivitas Bubuk Biji Pepaya (Carica Papaya Linnaeaus) Sebagai Larvasida Alami Terhadap Kematian Larva Aedes Aegypty Tahun 2015", Eksakta: Berkala Ilmiah Bidang MIPA, 18(01), pp. 12-18. doi: https://doi.org/10.24036/eksakta/vol18-iss01/12.

237. Ramli, R., Jonuarti, R. and Hartono, A. (2017) "Analisis Struktur Nano Dari Lapisan Tipis Cobalt Ferrite Yang Dipreparasi Dengan Metode Sputtering", Eksakta: Berkala Ilmiah Bidang MIPA, 18(01), pp. 46-53. doi: https://doi.org/10.24036/eksakta/vol18-iss01/16.

238. Sanjaya, H. (2017) "Degradasi Methylene Blue Menggunakan Katalis Zno-Peg Dengan Metode Fotosonolisis", Eksakta: Berkala Ilmiah Bidang MIPA, 18(02), pp. 21-29. doi: https://doi.org/10.24036/eksakta/vol18-iss02/45.

239. Ningsih, S. K. (2017) "Sintesis Dan Karakterisasi Nanopartikel Zno Doped Cu2+ Melalui Metoda Sol-Gel”, Eksakta: Berkala Ilmiah Bidang MIPA, 18(02), pp. 39-51. doi: https://doi.org/10.24036/eksakta/vol18-iss02/51.

240. Saiya, A. (2017) "Analisis Residu Klorpirifos Dalam Sayuran Kubis Dengan Metode Hplc Di Beberapa Pasar Tradisional Di Sulawesi Utara", Eksakta: Berkala Ilmiah Bidang MIPA, 18(02), pp. 77-85. doi: https://doi.org/10.24036/eksakta/vol18-iss02/57.

241. Syafei, N. (2017) "Analisa Fenomena Korosi Pelat Pipa Baja Karbon Api 51-X65 Dalam Larutan 250 Ml Asam Asetat Dan 4750 Ml Aquades Pada Kondisi Gas Co2 Dan H2s Jenuh Pada Suhu Ruang", Eksakta: Berkala Ilmiah Bidang MIPA, 18(02), pp. 113-120. doi: https://doi.org/10.24036/eksakta/vol18-iss02/63.

242. Tutuarima, T. (2017) "Sifat Fisik Dan Kimia Marmalade Jeruk Kalamansi (Citrus microcarpa) : Kajian Konsentrasi Pektin Dan Sukrosa Physical and Chemical Properties of Marmalade Citrus of Calamondin (Citrus microcarpa) : Study of Pectin and Sucrose Concentrations", Eksakta: Berkala Ilmiah Bidang MIPA, 18(02), pp. 164-172. doi: https://doi.org/10.24036/eksakta/vol18-iss02/73.

243. Ruswandi, R. (2018) "Determination of Fructose Content resulted by Inulin Hydrolysis with DNS as Oxidizer", Eksakta: Berkala Ilmiah Bidang MIPA, 19(1), pp. 14-23. doi: https://doi.org/10.24036/eksakta/vol19-iss1/102.

244. Sanjaya, H. (2018) "Degradasi Metil Violet Menggunakan Katalis Zno-Tio2 Secara Fotosonolisis", Eksakta: Berkala Ilmiah Bidang MIPA, 19(1), pp. 91-99. doi: https://doi.org/10.24036/eksakta/vol19-iss1/131.

245. Hidayani, T. (2018) "Grafting Polipropilena Dengan Maleat Anhidrida Sebagai Pengikat Silang Dengan Inisiator Benzoil Peroksida", Eksakta: Berkala Ilmiah Bidang MIPA, 19(1), pp. 56-62. doi: https://doi.org/10.24036/eksakta/vol19-iss1/127.

246. Prabowo, H. (2018) "Penyelidikan Kelayakan Kimia Dan Penyebaran Cadangan Pasir Besi Daerah Tiku Kabupaten Agam Untuk Bahan Baku Semen Pada Pt. Semen Padang”, Eksakta: Berkala Ilmiah Bidang MIPA, 19(1), pp. 39-42. doi: https://doi.org/10.24036/eksakta/vol19iss $1 / 121$.

247. Syafei, N. (2018) "Riset Material Analisa Fenomena Korosi Pelat Pipa Baja Karbon Api 51X65 Dalam Larutan 7900 Ml Air Laut Dan 100 Ml Amoniak Pada Kondisi Gas Co2 Dan H2s Jenuh Pada Suhu Ruang.", Eksakta: Berkala Ilmiah Bidang MIPA, 19(1), pp. 7-13. doi: https://doi.org/10.24036/eksakta/vol19-iss1/83.

248. Parbuntari, H., Prestica, Y., Gunawan, R., Nurman, M. and Adella, F. (2018) "Preliminary Phytochemical Screening (Qualitative Analysis) of Cacao Leaves (Theobroma cacao L.)", Eksakta: Berkala Ilmiah Bidang MIPA, 19(2), pp. 40-45. doi: https://doi.org/10.24036/eksakta/vol19-iss2/142.

249. Dinata, M. and Soehardi, F. (2018) "Factor Analysis of Physics Chemistry Waters that Affects Damage Safety Cliff on the Outskirts of River Siak", Eksakta: Berkala Ilmiah Bidang MIPA, 19(2), pp. 46-49. doi: https://doi.org/10.24036/eksakta/vol19-iss2/143.

250. Sofyanita, S. and Octaria, Z. (2018) "Fenthion Compound Degradation in the Pesticide Bayleton $500 \mathrm{ec}$ in Sonolysis, Ozonolysis and Sonozolysis with Addition of TiO2anatase", Eksakta: $\quad$ Berkala Ilmiah Bidang MIPA, 19(2), pp. 70-79. doi: https://doi.org/10.24036/eksakta/vol19-iss2/153. 
251. Harahap, F. and Lubis, L. (2018) "Analysis of Heavy Metals Distribution in the River Town of Hamasaki's Rod Padangsidimpuan”, Eksakta: Berkala Ilmiah Bidang MIPA, 19(2), pp. 5056. doi: https://doi.org/10.24036/eksakta/vol19-iss2/149.

252. Syafei, N., Hidayat, D., Emilliano, E. and Men, L. (2018) "Analysis Cracking Corrosion on Carbon Steel Pipes API 5L-X65 In Solution $7700 \mathrm{ml}$ Aquades, $250 \mathrm{ml}$ Acetic Acid and $50 \mathrm{ml}$ Ammonia with Gas CO2 and H2S in Saturation Condition", Eksakta: Berkala Ilmiah Bidang MIPA, 19(2), pp. 21-31. doi: https://doi.org/10.24036/eksakta/vol19-iss2/138

253. Chaidir, z., Zainul, R., Nurakhbari, D., \& Salim, M. (2016, September 24). Optimization of Spirulina Platensis Culture for Antioxidant Production. https://doi.org/10.17605/OSF.IO/FD6E4

254. Zainul, R., \& Prima, C. B. (2017, June 29). Desain Geometri Sel PV. https://doi.org/10. 31227/osf.io/7n 8 t4 